Inequality in an OLG economy with heterogeneous cohorts and pension systems

Marcin Bielecki, Krzysztof Makarski, Joanna Tyrowicz

Foundation of Admirers and Mavens of Economics Group for Research in Applied Economics 


\section{Inequality in an OLG economy with heterogeneous cohorts and pension systems}

\author{
Marcin Bielecki \\ National Bank of Poland \\ University of Warsaw
}

\author{
Krzysztof Makarski \\ FAME|GRAPE \\ Warsaw School of Economics \\ National Bank of Poland
}

\author{
Joanna Tyrowicz \\ FAME|GRAPE \\ University of Warsaw
}

\section{Abstract}

We analyze the consumption and wealth inequality in an OLG model with obligatory pension systems. Our framework features within cohort heterogeneity of endowments (individual productivities) and heterogeneity of preferences (preference for leisure and time preference). We allow for population aging and gradual productivity slowdown. We show four main results. First, longevity increases substantially aggregate consumption inequality and wealth inequality, regardless of the pension system features. Second, the effect of a pension system reform from a defined benefit to a defined contribution works to reinforce the consumption inequality and reduce the wealth inequality. Third, minimum pension benefits are able to counteract a part of that increase in inequality, at a fiscal cost. Fourth the minimum pension benefit guarantee addresses mostly the inequality which stems from differentiated endowments and not that which stems from heterogeneous preferences..

Keywords:

majority voting, pension system reform, welfare

JEL Classification

H55, E17, C60 C68, E21, D63

Corresponding author

Krzysztof Makarski, k.makarski@grape.org.pl

\section{Acknowledgements}

Earlier versions of this paper have received extremely valuable comments from Fabian Kindermann, Patrick Puhani, Dirk Niepelt, Hans Fehr, Martyna Kobus, Nicoleta Ciurila, Damiaan Chen, Jan Hagemejer, Lukasz Drozd, Borys Grochulski and Jaromir Nosal as well as participants of NIESR, GRAPE, NBP and SGH seminars for insightful suggestions. Refreshing comments and remarks were also received during ICMAIF 2015, NBP Macroeconomic Workshop 2015, World Congress of Comparative Economics 2015, WIEM 2015 and Netspar 2015, MoPaCT workshop (Helsinki, 2016), workshops in University of Mannheim (2016), Higher School of Economics (2016) and Society for Economic Dynamics 2017. We also thank two anonymous referees for thorough and well-spirited comments. Earlier versions of this paper benefited greatly from cooperation with Marcin Waniek, whose help and advice is gratefully acknowledged. Jan Jakub Woznica provided wonderful research assistance. The support of National Science Centre (grant UMO2012/01/D/HS4/04039 and UMO-2014/15/G/HS4/04638) is gratefully acknowledged. All opinions expressed are those of the authors and have not been endorsed by NSC nor NBP. The remaining errors are ours.

\section{Published by: $\quad$ FAME | GRAPE \\ ISSN: 2544-2473}

(C) with the authors, 2017

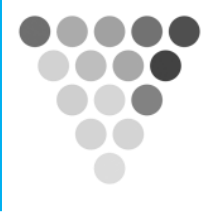

Foundation of Admirers and Mavens of Economics 


\section{Introduction}

It is not controversial to state that pension systems are an important force behind the changes of income distribution. It is an empirical regularity that both income and consumption are not equal for young, prime and old-aged individuals, thus generating inequality captured by inequality measures from the cross-sectional data. A big part of this divergence can be explained by redistributive properties of the pension system (see Storesletten et al. 2004). Pension systems can affect not only income and consumption inequality but also wealth inequality. For example, Domeij and Klein (2002) show that the generosity of the Swedish pension system effectively crowds out private savings among a large fraction of the population, making wealth inequality measures twice as high as income inequality measures in this country. Clearly, the fact that a fraction of population accumulates non-zero wealth also suggests that there are important within cohort differences in ability and/or willingness to save. Indeed, Hairault and Langot (2008) show that low productivity individuals have almost no ability to accommodate for adverse changes in the redistributive properties of the pension systems, hence amplifying the effects of these reforms on inequality and welfare (similar effect is confirmed by Song 2011).

In response to challenges posed by decreasing fertility and increasing longevity, a large body of literature analyses the effects of the pension system reforms that aim at linking pensions with contributions on the individual level. Papers in this strand of literature frequently rely on relatively restrictive assumption of within cohort homogeneity (see Fehr 2009). With individuals identical within cohorts, life-cycle patterns of income are the only sources of potential consumption and wealth inequality.

Within cohort inequality was introduced to the models as a way to address these shortcomings. The inequality can be modeled as idiosyncratic shocks to income, labor supply or life duration - see for example Fehr et al. (2008), Hairault and Langot (2008), Fehr and Kindermann (2010), Bucciol (2011), Cremer and Pestieau (2011), Kumru and Thanopoulos (2011), Kaganovich and Zilcha (2012), Fehr and Uhde (2014), St-Amant and Garon (2015), Kindermann and Krueger (2014). This way of operationalizing heterogeneity is valuable from many research perspectives ${ }^{1}$, but it is not without limitations (see Bourguignon and Spadaro 2006). Most notably, it neglects other sources of heterogeneity like preferences or differences of abilities. Therefore, it does not offer a full picture of the effects of redistributive instruments within the pension system. In fact, as demonstrated by Castañeda et al. (2003), an economy populated with identical agents faced with uninsured idiosyncratic shocks to individual productivity cannot reproduce the actual inequality distributions unless the quantitative features of the social security system are accounted for (see also recently Benhabib et al. 2015, De Nardi and Yang 2016, Kanbur and Stiglitz 2016). ${ }^{2}$

\footnotetext{
${ }^{1}$ As noted by Nishiyama and Smetters (2007), while privatizing social security can improve labor supply incentives, it can also reduce risk sharing. With randomized and non-insurable shocks to individual productivity, the original conclusions from a highly stylized model by Feldstein (1995) do not necessarily hold. Similar conclusions originate from models incorporating time inconsistency into the consumer choice, İmrohoroğlu et al. (2003), Bassi (2008), Fehr et al. (2008), van de Ven and Weale (2010), Fehr and Kindermann (2010), Kumru and Thanopoulos (2011)

${ }^{2}$ In fact, optimal marginal tax rates should vary with age, in response to changing wealth as well as survival probabilities, whereas - as demonstrated by Gervais (2012) - they vary only in response to the earned income age profile, thus making the progressivity observed in many advanced economies a highly imperfect substitute to
} 
Our objective is to provide a way to study distributional effects of aging and pension system reform. To this end, we begin the simulations with an economy calibrated to replicate crosssectional distributions observed in the data. Hence, we propose an economy populated with agents heterogeneous ex ante within the same birth cohort. This heterogeneity is realized at birth and accounts for both earning abilities and preferences. We introduce complex, multidimensional patterns of heterogeneity, while maintaining the computational time within reasonable limits - both of which would not have been feasible with a stochastic setup. Such modeling approach is similar to Hénin and Weitzenblum (2005) and McGrattan and Prescott (2013). In such an economy we study the distributional effects of aging, pension system reform and - finally - the effectiveness of instruments aimed at mitigating old-age poverty as well as consumption and wealth inequality.

Our contribution to the literature is threefold. First, in a setup calibrated to the features of Polish economy we document the relevance of longevity for wealth and consumption inequality. In particular, we show important differences between the defined benefit (DB) pension system and the defined contribution (DC) pension system. This comparison appeals as policy relevant, because most of the economies have either a DB system or are already in transition to a DC system (see Gruber and Wise 2004), while gradual increases in longevity are faced literally everywhere around the globe. Following the advice of international financial institutions, most transition economies in Central and Eastern Europe - including Poland - reformed their pension systems, replacing a DB system with a DC one. Such a reform increases substantially consumption inequality, on top of the increase induced by changes in longevity.

Second, we test the redistributive effectiveness and fiscal consequences of policy instruments aimed at reducing old-age inequality: minimum pension benefit guarantee and lump sum indexation. Both are policy relevant in a sense, that the minimum pension benefit guarantee tends to exist in most advanced and emerging economies, whereas lump sum indexation are widely considered a useful way to reduce inequality in pension benefits, and hence old-age consumption inequality (see Gruber and Wise 2004). Minimum pension benefit guarantee is likely to induce high fiscal costs. Moreover, in DC systems, it provides labor supply disincentives to workers below the threshold earnings. Lump sum indexation, by contrast, is fiscally neutral. In essence, it redistributes from high earning individuals to low earning ones, but limiting the scope of the redistribution to the retirees. The simulations reveal that minimum pension benefits guarantee is indeed effective in reducing inequality, cutting in half the increase in consumption inequality induced by a reform from DB to DC pension systems. By contrast, lump sum indexation is insufficient to influence inequality measures in any meaningful way.

Finally, we propose a way to evaluate the potential perverse effects of the analyzed policy instruments. Indeed, heterogeneous preferences become increasingly used in macroeconomic research. As early as in 1990s, Krusell and Smith $(1997,1998)$ introduced differentiated time preference. Similarly, Lockwood and Weinzierl (2015) argue that preference heterogeneity reduces desirable redistribution. They refer to the notion of compensating for unequal opportunities but not for differentiated choices, as suggested by Fleurbaey and Maniquet (2005). We rely on these premises and on the partial equilibrium comparisons to discern between the 
changes in the inequality that help to alleviate consequences of dispersion in endowments and those that address the dispersion which stems from heterogeneity in preferences. One important difference relative to earlier studies is that we explicitly take into account the role of heterogeneous preferences. In addition to differentiated productivities, some studies - e.g. Hénin and Weitzenblum (2005) - allow for differentiated mortality risk within cohort. We are unaware of any study that would allow for heterogeneity in preferences in the OLG framework. While both of the popular instruments analyzed in our study are aimed at reducing inequality (in terms of consumption and wealth), their general equilibrium effects are not likely to be similar. Thus, it is particularly relevant to observe which types of inequality these instruments address best. Consider a world with an entirely private social security with perfect annuities and homogeneous survival probability within each cohort. In such a setting, consumption inequality at older ages can only result from two sources: agents did not want to save the same amount (differentiated preferences) or they could not save the same amount (differentiated endowments). Hence, we tackle the policy relevant angle of which types of equity is preferred by the societies: that of outcomes or that of opportunities (see Fleurbaey and Maniquet 2006, Lockwood and Weinzierl 2015, for the detailed treatment of why it matters for policy intervention). In our setting inequality of opportunity - that which stems from differentiated endowments - contributes less to overall inequality than heterogeneous endowments. Yet, it is the endowments channel that is more effectively addressed via minimum pension benefits.

Our paper is structured as follows. We begin by presenting the model in section 2, discussing the similarities and differences with reference to the previous studies in the field. We then move to describing in detail the model calibration in section 3. While our setting is fairly standard, there are some features of the model that respond to the characteristic of the actual reform that was undertaken and which we use for calibrating the model - both of which are explained in detail in these sections. Subsequently, in section 4 we analyze the effectiveness of two policy instruments: minimum pension benefits guarantee and lump sum taxation. Step by step we show the results for the DB systems and DC systems, comparing them explicitly. Finally, in section 5 we discuss the results of our decomposition experiment, which isolates the inequality of endowments and inequality of preferences. We conclude the paper by discussing the limitations of our study and policy implications.

\section{The model}

We develop a general equilibrium overlapping generations model, with exogenous but time varying technological progress, decreasing fertility and increasing longevity. Economy is populated by $\mathcal{K}$ classes of agents with differentiated endowments and preferences (within one function family), who live for $j=1,2, \ldots, J$ periods facing a time and age specific mortality with unconditional probability of survival denoted by $\pi_{j, t}$.

\subsection{Consumers}

Consumers are born at the age of 20 , which we denote $j=1$, at which time they are randomly assigned with individual productivity multiplier $\omega_{k}$ as well as utility function parameters. These 
values do not change until the agent dies. Thus, a subcohort $k=1,2, \ldots, \mathcal{K}$ of agents within cohort $j$ is described uniquely by assigned values of $\phi, \omega$ and $\delta .^{3}$

The year of birth determines fully the survival probabilities at each age $j$. At all points in time, consumers who survive until the age of $j=J$ die with certitude. ${ }^{4}$ The share of population surviving until older age is increasing, to reflect changes in longevity. Decreasing fertility is operationalized by a falling number of births. The data for mortality and births come from a demographic projection until 2060. As of this year we gradually stationarize model population to reach the final steady state of unchanging population size and structure. This modeling choice is conservative in the sense that defined benefit systems are more fiscally viable in stable populations.

At each point in time $t$ an individual of age $j$ and subcohort $k$ born at time $t-j+1$ consumes a non-negative quantity of a composite good $c_{j, k, t}$ and allocates $l_{j, k, t}$ time to work (total time endowment is normalized to one). In each period $t$ agents at the age of $j=\bar{J}$ retire. Consumers can also accumulate assets $a_{j, k, t}$ that earn the interest rate $r_{t}$. Consequently, consumers lifetime utility is as follows:

$$
U_{j, k, t}=u_{k}\left(c_{j, k, t}, 1-l_{j, k, t}\right)+\sum_{s=1}^{J-j} \delta_{k}^{s} \frac{\pi_{j+s, t+s}}{\pi_{j, t}} u_{k}\left(c_{j+s, k, t+s}, 1-l_{j+s, k, t+s}\right)
$$

where discounting takes into account time preference $\delta_{k}$ and probability of survival. The instantaneous utility function is given by:

$$
u_{k}\left(c_{j, k, t}, l_{j, k, t}\right)=\phi_{k} \ln c_{j, k, t}+\left(1-\phi_{k}\right) \ln \left(1-l_{j, k, t}\right) \quad \text { with } \quad l_{j, k, t}=0 \quad \forall j \geq \bar{J} .
$$

Household income consists of earned labor income, capital gains, pension income, bequests and lump-sum taxes/transfers. Labor income tax $\tau^{l}$ and social security contributions $\tau$ are deducted from gross earned labor income to yield disposable labor income. ${ }^{5}$ Interest earned on assets $r$ is taxed with $\tau^{k}$. In addition, there is a consumption tax $\tau^{c}$ as well as a lump sum tax/transfer $\Upsilon$ equal for all subcohorts, which we use to set the budget deficit in concordance with the data. Thus, agent of age $j$ in period $t$ maximizes her lifetime utility function $U_{j, k, t}$ subject to the following sequence of budget constraints:

$$
\begin{aligned}
\left(1+\tau_{t}^{c}\right) c_{j, k, t}+a_{j, k, t} & =\left(1-\tau_{t}^{l}\right)(1-\tau) w_{t} \omega_{k} l_{j, k, t} & \leftarrow \text { labor income } \\
& +\left(1+\left(1-\tau_{t}^{k}\right) r_{t}\right) a_{j-1, k, t-1} & \leftarrow \text { capital income } \\
& +\left(1-\tau_{t}^{l}\right) b_{j, k, t} & \leftarrow \text { pension income } \\
& +b e q_{j, k, t} & \leftarrow \text { bequests } \\
& -\Upsilon_{t} & \leftarrow \text { lump-sum tax }
\end{aligned}
$$

When working, the agent is constrained by earned disposable income, bequests and assets accumulated in previous periods with net interest. When retired, the agent is constrained

\footnotetext{
${ }^{3}$ See Section 3 for the detailed description of the calibration procedure.

${ }^{4}$ The availability of the demographic data and forecast until the age of 100 puts a limit at $J=80$.

${ }^{5}$ Note that labor is taxed only once social security contribution is paid. This setup follows legislation in many countries and makes pension benefits subject to labor income tax, $\tau^{l}$, during the retirement.
} 
by disposable pension benefit, bequests and assets accumulated in previous periods with net interest. Agents have no bequest motive, but since survival rates are lower than one, in each period $t$ a certain fraction of subcohort $(j, k)$ leaves unintended bequests, which are distributed within their subcohort. ${ }^{6}$

In our setting, the agents share a family of utility functions, but the actual trade-off between consumption and leisure (the intra-temporal choice) as well as preference for the future (the inter-temporal choice) are heterogeneous within cohort. The agents are hence fully rational in a sense that the decision heuristic for the agents follows directly from solving the lifetime utility optimization problem and the same holds for the firms. Thus, this approach is similar to multi-agent systems with all the advantages of the general equilibrium setting. Whereas a standard OLG model aggregates over cohorts to obtain general equilibrium conditions, an OLG model with MAS aggregates over classes of economic agents within a cohort and only then over cohorts, see Ferber (1999), Tesfatsion (2002), Wooldridge (2009). Thus, the solution in the equilibrium relies on the same premises as in standard a OLG model with a representative agent, as long as agents share the family function for preferences. ${ }^{7}$

\subsection{Production}

Individuals supply labor (time) to the firms. The amount of effective labor used at time $t$ by a production firm is $L_{t}=\sum_{j=1}^{\bar{J}-1} \sum_{k=1}^{\mathcal{K}} N_{j, k, t} \omega_{k} l_{j, k, t}$, where $N_{j, k, t}$ is the size of a $(j, k)$ subcohort at time $t$.

Perfectly competitive producers supply a composite final good with the Cobb-Douglas production function $Y_{t}=K_{t}^{\alpha}\left(z_{t} L_{t}\right)^{1-\alpha}$ that features labor augmenting exogenous technological progress denoted as $\gamma_{t}=z_{t+1} / z_{t}$. Standard maximization problem of the firm yields the real wage $w_{t}=(1-\alpha) K_{t}^{\alpha} z_{t}^{1-\alpha} L_{t}^{-\alpha}$ and the return on capital $r_{t}=\alpha K_{t}^{\alpha-1}\left(z_{t} L_{t}\right)^{1-\alpha}-d$, where $d$ denotes the depreciation rate of capital.

\subsection{Pension system}

We consider a pay-as-you-go defined benefit system (PAYG DB), with an exogenous contribution rate $\tau$ and an exogenous replacement rate $\rho$, thus

$$
b_{\bar{J}, k, t}=\rho \cdot\left(w_{t-1} \cdot \omega_{k} \cdot l_{\bar{J}-1, k, t-1} \cdot(1-\xi)+\bar{w}_{t-1} \cdot \xi\right)
$$

holding $\forall_{k}$ where $\bar{w}_{t-1}$ denotes previous period's average wage and $\xi$ denotes the share of pension that is determined by an average wage in the economy, hence redistributive. ${ }^{8}$ The

\footnotetext{
${ }^{6}$ This assumption limits the scope for within-cohort redistribution back-doors. Moreover, it appears plausible: households are typically formed by individuals of similar income and social status.

${ }^{7}$ The reliance on the MAS has recently become more and more common, see as it could seem, Axtell (2000), Windrum et al. (2007), Wooldridge (2009). An agent is a program/routine capable of optimizing, as suggested by standard representative agent first order conditions. Such program can be run on a system populated by 'agents' with differentiated preferences and endowments, see Russell and Norvig (1995), Wooldridge and Jennings (1995), Kirman (1997).

${ }^{8}$ Legislation sets $\xi$ in Poland at 0.24 .
} 
system collects contributions from the working and pays benefits to the retired:

$$
\sum_{j=\bar{J}}^{J} \sum_{k=1}^{\mathcal{K}} N_{j, k, t} b_{j, k, t}=\tau w_{t} L_{t}+\text { subsidyt }
$$

where subsidyt is a subsidy/transfer from the government to balance the pension system. The benefits are indexed annually with the payroll growth:

$$
1+r_{t}^{I}=\frac{w_{t} L_{t}}{w_{t-1} L_{t-1}}
$$

We also consider a defined contribution system (DC). The DC pension system collects contributions and uses them to cover for contemporaneous benefits, but pays out pensions computed on the basis of accumulated contributions, as given by equation:

$$
b_{\bar{J}, k, t}=\frac{\sum_{s=1}^{\bar{J}-1}\left[\prod_{\iota=1}^{s}\left(1+r_{t-\bar{J}+\iota}^{I}\right)\right] \tau_{t-\bar{J}+s} \omega_{k} w_{t-\bar{J}+s} l_{s, k, t-\bar{J}+s}}{\sum_{s=\bar{J}}^{J} \pi_{s, t}}
$$

where $r_{t}^{I}$ is the accrual rate defined by the rate of the payroll growth, equation (10). Analogously to the PAYG DB case, the benefits are indexed annually with payroll growth.

Our economy starts with a DB and gradually shifts to DC, with an unchanged contribution rate $\tau$. The transition is gradual in a sense that the cohorts with $j \geq \bar{J}$ at the time of the reform receive pensions in an unchanged manner. The same applies to the oldest 20 cohorts of workers, who remain in the DB system. Hence, only workers with $j<\bar{J}-20$ receive pensions from the formula given by equation (11). For all the years of work under the DB system, we compute implied contributions to the DC system as if these workers were covered by the DC system from the first contribution. Only then actual pension benefits are computed.

\subsection{The government}

The government collects taxes ( $\tau^{k}$ on capital, $\tau^{l}$ on labor and $\tau^{c}$ on consumption, as well as a lump-sum tax/transfer $\Upsilon$ ) and spends a fixed share of GDP on unproductive yet necessary consumption $G=g \cdot Y$. Government balances the pension system. Given that the government is indebted, it naturally also services the debt outstanding.

$$
\begin{aligned}
& T_{t}=\sum_{j=\bar{J}_{t}}^{J} \sum_{k=1}^{\mathcal{K}} N_{j, k, t}\left[\tau_{t}^{l}\left((1-\tau) w_{t} \omega_{k} l_{j, k, t}+b_{j, k, t}\right)+\tau_{t}^{c} c_{j, k, t}+\tau_{t}^{k} r_{t} s_{j-1, k, t-1}+\Upsilon_{t}\right] \\
& T_{t}+\left(D_{t}-D_{t-1}\right)=G_{t}+\text { subsidy }_{t}+r_{t} D_{t-1}
\end{aligned}
$$

In the initial and final steady state $D_{t}$ is set at $45 \%$ share in GDP, in concordance with the state of economy at the moment of calibration. We calibrate $\Upsilon_{t}$ in the steady state to match the deficits and debt to maintain the long run debt/GDP ratio fixed and keep it unchanged throughout the whole path. On the transition path the values of $\Upsilon$ and $G$ are held fixed (per effective unit of labor) at the level from the initial steady state. If there is deficit in the budget, consumption taxes adjust to allow the budget balancing, following equation (12). 


\subsection{Market clearing and equilibrium conditions}

In the equilibrium the goods market clearing condition is defined as follows

$$
\sum_{j=1}^{J} \sum_{k=1}^{\mathcal{K}} N_{j, k, t} c_{j, k, t}+G_{t}+K_{t+1}=Y_{t}+(1-d) K_{t}
$$

This equation is equivalent to stating that at each point in time the price for capital and labor would be set such that the demand for the goods from the consumers, the government and the producers would be met. This necessitates clearing in the labor and capital markets.

$$
\begin{aligned}
L_{t} & =\sum_{j=1}^{\bar{J}-1} \sum_{k=1}^{\mathcal{K}} N_{j, k, t} \omega_{k} l_{j, k, t} \\
K_{t+1}+D_{t} & =\sum_{j=1}^{J} \sum_{k=1}^{\mathcal{K}} N_{j, k, t} a_{j, k, t},
\end{aligned}
$$

where $a_{j, k, t}$ denotes private assets.

An equilibrium is an allocation $\left\{\left(c_{1, k, t}, \ldots, c_{J, k, t}\right),\left(a_{1, k, t}, \ldots, a_{J, k, t}\right),\left(l_{1, k, t}, \ldots, l_{J, k, t}\right), K_{t}, Y_{t}, L_{t}\right\}_{t=0}^{\infty}$ and prices $\left\{w_{t}, r_{t}\right\}_{t=0}^{\infty}$ such that:

- for all $t \geq 1$, for all $j \in[1, J]$ for all $k \in[1, \mathcal{K}]\left(\left(c_{j, k, t}, \ldots, c_{J, k, t+J-j}\right),\left(s_{j, k, t}, \ldots, s_{J, k, t+J-j}\right)\right.$ and $\left(l_{1, k, t}, \ldots, l_{J, k, t+J-j}\right)$ solve the problem of an agent at the age of $j$ from subcohort $k$ in period $t$, given prices;

- prices are given by: $r_{t}=\alpha K_{t}^{\alpha-1}\left(z_{t} L_{t}\right)^{1-\alpha}-d$ and $w_{t}=(1-\alpha) K_{t}^{\alpha} z_{t}^{1-\alpha} L_{t}^{-\alpha}$

- government sector is balanced, i.e. (9), (12) and (13) are satisfied;

- markets clear.

\subsection{Model solving}

This section describes the construction of the multi-agent model. It consists of three different types of agents - government agent, private sector agent and multiple subcohorts.

Subcohorts represent parts of a cohort that share the same parametrization, that is productivity $\omega$, preference for leisure $\phi$ and time preference $\delta$. In each year of the simulation each subcohort either divides her time between labor and leisure given equations (1)-(2), and receives salary from the private sector agent (if she is working) or receives benefits from the government agent (if she is retired), depending on the age of this cohort. In both cases she pays taxes to the government and spends some of its resources on consumption. Every subcohort decides about intra-temporal division of time to work and leisure and inter-temporal choice of consumption and assets in order to maximize lifetime utility, following the budget constraint (3).

Government agent represents pension system and tax-collecting. Her responsibilities in the system consist of collecting taxes from all the subcohorts and paying benefits to retired subcohorts. The government agent can be DB or DC. If the government is a DC, it can be with 
or without the minimum pension benefit guarantee and lump sum taxation. In total that yields 4 classes of this agent. Only one of them participates in a given instance of the simulation. Government agent is given a certain fiscal closure rule, i. e. a rule that translates government expenditures and tax base to tax rates, see equations (12)-(13).

Private sector represents companies from the private sector. She is the recipient of labor supplied by subcohorts, she keeps track of capital value in the system and calculates salaries for subcohorts given the aggregate production function.

In the simulation process the objective is to calculate the effects of different pension systems on inequality in a society. To achieve this objective, the system calculates two steady states, representing initial and final year of modeled period, and then computes transition path between them. General algorithms for computing steady state and transition paths are similar. It is an iterative process using the Gauss-Seidel method. In each iteration, choices of agents are updated. The process stops when the difference between the capital from the new iteration is indiscernible from the previous iteration, i.e. smaller than a given parameter $\epsilon$. On a transition path the optimization criterion relies on a sum of $\epsilon$ from each period. The parameter $\epsilon$ has been set to $10^{-14}$ in the steady states and a sum over all $T$ set to $10^{-4}$ for a transition path.

Every iteration consists of the same major steps. Government, basing on capital calculated in the previous iteration (or initial capital in first iteration) and parametrization of the model, computes tax rates. Given these rates and the structure of the pension system, government also computes pension benefits for the retired cohorts. Given the amount of capital and labor, firms set interest rates and wages. Given the tax rates, interest rates, and wages (as well as received bequests), subcohorts choose labor supplied for each year of life, as well as consumption and assets. Given these choices, assets are aggregated to capital, to be compared with capital from the previous iteration. If the two values satisfy the norm condition, the process finishes. Otherwise, a new iteration starts.

\section{Calibration}

The model is calibrated to replicate features of Polish economy and Polish pension system. An economy begins with a DB system, which functioned in Poland until 1999. Pensions were granted to all individuals above age 65 (60 for women), with at least 25 years of working experience (20 for women), with years in education accruing to the working experience. Experience was not recalculated to full-time equivalents, i.e. part-time employment counted the same way as full-time employment. The nominal replacement rate was applied to a relatively complex formula, which had a social component and a private component. The social component was related to an average wage in the economy. Meanwhile, the rules for the private component changed many times since 1990. Initially, the rule was to utilize as a base the monthly wage from the last month prior to claiming the pension. With subsequent legislative changes, that base was changed to an average over the last year, then over the last three years, and eventually, the best 10 out of the last 20 years of working career, including career breaks such as unemployment or temporary disability leaves.

As of 1999, Poland adopted a defined contribution system for all cohorts born in 1958 or 
younger. ${ }^{9}$ All prior pension obligations were continued, whereas individuals close to retirement at the moment of the reform were to participate in a mixed system, which partly uses DB rules and partly uses DC rules, with proportions of the DC rules growing for younger cohorts. The mixed system was to become effective as of 2009 for women and 2014 for men. ${ }^{10}$ Our calibration replicates the pre-1999 DB features, the post-1999 DC features and the original design of the mixed transition system.

First we describe the structural parameters of the model, i.e. those parameters that do not change between the baseline and reform scenarios. All structural macroeconomic parameters are presented in Table A1. Below we discuss in detail the macroeconomic assumptions as well as the underlying sources of microeconomic heterogeneity.

Demographics. The Eurostat demographic projection for Poland serves as a source for the sizes of new cohort arriving each year in the economy, i.e. $j=1$ at each point in time $t$. The same source provides sizes of each cohort at consecutive ages, which serves as basis for computing the survival probabilities $\pi_{j, t}$. The projection is available until 2060. We assume that both birth rate and survival rates flatten after that period, so our population stabilizes after 2140 .

Technological progress. The model accounts for technological progress in labor augmenting form. We input the projected path on future technological growth rates basing on the forecast by the Aging Work Group of the European Commission, which provides this time series for all EU Member States. The overall assumption behind the forecast is that countries with lower per capita income will be catching up in terms of labor productivity, but eventually there is a steady convergence towards the long term value of $1.5 \%$ rate of labor productivity growth per annum, common for all EU countries.

Taxes. There are no tax redemptions on capital income tax, so de iure and de facto tax rates were set equal, which implies $\tau_{k}=19 \%$. Labor income tax $\left(\tau_{l}\right)$ was set at effective $19 \%$, which matches the ratio of labor income tax revenues to GDP in 1999 (4.9\%). Consumption tax $\tau_{c}$ was set at 11\%, which matches the ratio of revenues from this tax to GDP in 1999 (7.4\%). The consumption tax is allowed to increase in the baseline and reform scenarios to keep the government budget constraint given in equation (13) in balance.

Pension system. The original replacement rate $\rho$ in the DB PAYG system was set to match the ratio of the pension benefits in GDP to 1999, i.e. 5\%. Subsequently, the social security contributions were set to reflect the size of deficit in the pension system (denoted in our model as subsidy), which amounted to 0.8\% of GDP in 1999.

\footnotetext{
${ }^{9}$ Cohorts born in 1968 or younger were also to start accruing pensions savings in a capital pillar, cohorts born between 1948 and 1968 could opt in to accruing pension savings in a capital pillar. The capital pillar was effectively abandoned in 2013, with the majority of accumulated savings nationalized and added to the pay-as-you-go pillar, we abstract from this feature of the pension system in our paper.

${ }^{10}$ In 2009 the legislation regulating the retirement age was changed (with subsequent changes to the whole pension system in 2011, 2013 and 2017). Hence, the pensions for the cohorts in the mixed transition system will be typically determined by DC rules.
} 
For cohorts already working under the defined benefits system, there is no data on accrued savings that could be used to compute pension benefits under defined contribution. We simulate the amount of the contributions using the formula implicit in equation (11) for all the cohorts active prior to the reform but participating in the reformed pension system. ${ }^{11}$

\subsection{Calibration of the productivity endowment and the preferences}

We have three dimensions of individual within cohort heterogeneity: two for preferences (leisure and time preference) and one for endowments (productivity). Following the previous insights from Hénin and Weitzenblum (2005), McGrattan and Prescott (2013) as well as Kindermann and Krueger (2014), we calibrate them using micro datasets. Unlike McGrattan and Prescott (2013), we rely on individual rather than household data for three main reasons. First, we cannot obtain reliable indicators of individual productivity from household budget surveys (individual income earned is not recoverable for many types of families). Second, both household budget survey data and the labor force survey data are self-reported, thus featuring all the well known problems such as rounding the reported values of earnings and hours. For these two reasons we rely on linked employer-employee data, collected biennially by central statistical offices of the UE, the Structure of Earnings Survey. It covers the enterprise sector and comprises a sample aproximately 20 times bigger than labor force or household budget surveys. The values of hours worked as well as earnings are reported in actual terms by the employers, which results in a substantially smoother distribution of the two variables. Finally, this way we also avoid confusion of wage income and capital income (see McGrattan and Prescott 2013).

Productivity endowment $\left(\omega_{k}\right)$. Since in our model the productivity endowment is allocated once for the entire lifetime, we use the early years in the career to obtain the distribution of these endowments. We estimate a standard Mincerian wage regression with education levels, occupation, industry and region controls, as well as the form of contract (fixed term or indefinite duration), form of employment (part-time, full-time, weekends, etc.). We use total hourly wage, including overtime and bonuses. The Mincerian wage regression was estimated for all individuals in the sample, so we had controls for age and experience (both linear and squared). Subsequently, we use fitted value of log earned hourly wage against the mean of this prediction for the individuals up to five years after labor market entry. This yields the final distribution of productivity multipliers of $\omega$, i.e.

$$
\omega_{k} \in\langle 0.70 \omega, 0.76 \omega, 0.84 \omega, 0.93 \omega, 0.98 \omega, 1.03 \omega, 1.08 \omega, 1.14 \omega, 1.20 \omega, 1.26 \omega\rangle^{12}
$$

is depicted in Figure 1a and has been used for calibration. These individual productivity endowment multipliers do not change during the lifetime, i.e. age-productivity profile is flat (see e.g. Deaton 1997, Börsch-Supan and Weiss 2016).

\footnotetext{
${ }^{11}$ Instead of implied savings, one could consider using data on actual accrued savings. However, inferring from the released sample of $1 \%$ of the records of the Social Insurance Fund, for many future retirees the records are empty. Although the legislation set a date until which citizens are obliged to claim their working period, in practice they can do so at any point in time, including just prior to the retirement.

${ }^{12}$ We run a similar analysis if median fitted value was to be the metric of endowments, the distribution is similar. The results are available upon request.
} 
Figure 1: Calibrations based on Structure of Earnings Survey, 1998

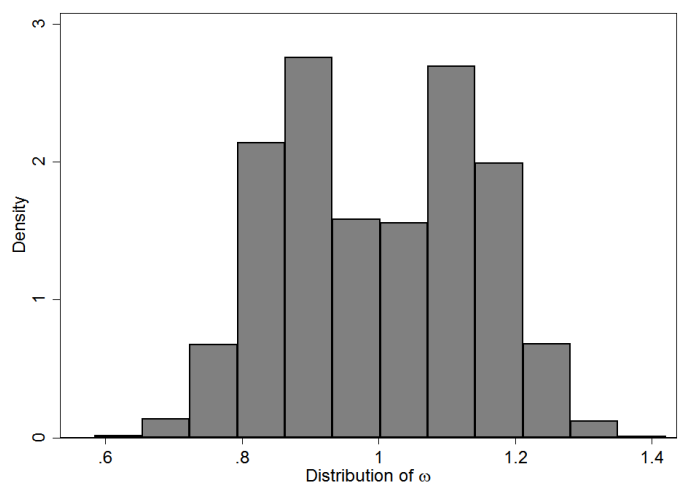

(a) calibration of productivity

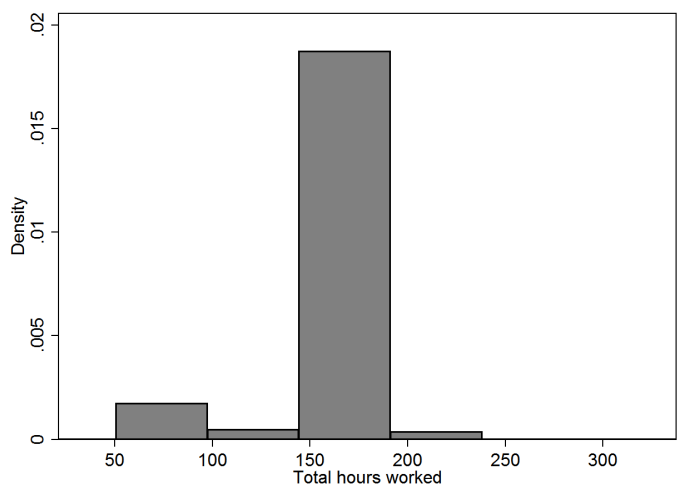

(b) calibration of preference for leisure

Leisure preference $\left(\phi_{k}\right)$. Agents' preference for leisure/consumption is directly responsible for the labor supply decisions, so we calibrate it to replicate the employment ratio of $56.8 \%$ in 1999. The final value of aggregate $\phi$ amounts to 0.500 , which seems plausible: average hours worked in Polish economy amount to app. $2050^{13}$, i.e. $51.5 \%$ of the total workable time.

However, individual preference for leisure is likely to be heterogeneous, with a fraction of population working part-time or not at all. Since preference for leisure is set once for the whole lifetime, we cannot directly replicate the distribution of working/non-working population (i.e. pick from data a share of individuals who do not currently participate in the labor market to proxy for a share of individuals who in the model never participate in the labor market), because we would automatically translate the initial structure of the inequality to the future via non-participation. Thus, we rely on reported hours actually worked in the Structure of Earnings Survey which range from $31 \%$ to $206 \%$ of the regular working time. We thus obtain the individual multipliers of the preference for leisure $\phi$, i.e. $\phi_{k} \in\langle 0.5 \phi, 1.0 \phi, 1.5 \phi, 2.0 \phi\rangle$. The distribution scaled by the mean hours worked is depicted in Figure $1 b .{ }^{14}$

Time preference $\left(\delta_{k}\right)$. The aggregate value $\delta$ was chosen to 0.981 match the interest rate of $7.0 \%$ on the asset portfolio, as observed in the data. ${ }^{15}$ Depreciation rate $d$ is calibrated to match the investment rate in the economy given $\delta$. The observed investment rate in the period between 1995 (first reliable post-transition data) and 2010 fluctuated between 19\% and 23\%, yielding an average of app. 21\%. We take this as a target value for calibrating the depreciation rate.

\footnotetext{
${ }^{13}$ Conference Board, averaged for 1999-2012 (ahwpol from The Conference Board Total Economy Database).

${ }^{14}$ Such calibration implicitly precludes that the variance in hours that come from outside the model stems from preferences, which is not likely to hold - either conceptually or in reality, see Stigler and Becker (1977). However, we use individual not household data on labor supply. Thus, the data does not permit identification of withinhousehold specialization or - to be put explicitly - households consisting of agents with different preferences.

${ }^{15}$ While this value may seem high, please note that we are calibrating to the case of a converging economy. For example, Nishiyama and Smetters (2007) calibrate interest rate to $6.25 \%$ for the US economy. Also, the average real annual rate of return at the level of $7.4 \%$, net of all the fees, with a balanced portfolio strategy was achieved on average by the open pension funds in the period 1999-2009. Thus, this value is not excessive, when compared to data or to the literature.
} 
There are no empirical counterparts for the individual $\delta_{k}$ for Poland. We rely on two sources of data about wealth inequality, to match the calibrated heterogeneity of $\delta$ parameter to replicate wealth inequality in the initial steady state. Davies et al. (2011) estimate the Gini coefficient for wealth inequality in Poland in 2000 at 65.7. This estimation overlaps with the timing of the initial steady state, however, the actual data underlying the estimation, come from a relatively small sample and a simplified survey of household wealth. A more thorough way to recording household wealth is pursued by the Household Finance and Consumption Network in the European System of Central Banks. The survey conducted by the National Bank of Poland in 2015 yields an estimate of wealth Gini coefficient of roughly 57.9. We calibrate the multipliers for $\delta$ to match the mid-range of these two values. We arbitrarily assume three classes for $\delta_{k}$ to encompass $40 \%$ of the cohort in the mid class, $30 \%$ of the cohort to be more impatient than average and the remaining $30 \%$ of the cohort to be more patient than average. This assumption combined with the target value yields $\delta_{k} \in\langle 0.988 \delta, 1.0 \delta, 1.012 \delta\rangle$.

\subsection{The implied within-cohort heterogeneity}

The adopted parametrization of the utility function generates substantial variation in income. In fact, the Gini coefficient for consumption in the initial steady state reaches approximately 21.5, which is a fair approximation of approximately 23-25 is observed in the data, see Brzeziński (2012). In terms of individual level differences, they are best observed in life cycle wealth profiles. More patient subcohorts with higher endowments and lower preference for leisure have substantially higher savings path than less patient subcohorts with lower endowments and higher preference for leisure.

In addition to a standard subcohort, which has no multipliers on preference for time $\delta$, for leisure $\phi$ and endowments $\omega$, Figures 2a to 3b depict life-time savings and labor supply patterns for several types of subcohorts. First, in Figures 2a and 3a we show life cycle paths for subcohorts with all multipliers over preferences set to 1 , but with differing multipliers on endowments. ${ }^{16}$ Analogously, in Figures $2 \mathrm{~b}$ and $3 \mathrm{~b}$ we keep endowment multipliers at 1 and display subcohorts with differentiated preferences. Heterogeneity in preferences translates to substantial differentiation in the propensity to save. In fact, at the retirement age, patient agents have wealth (i.e. accumulated lifetime savings) 2.3 times larger than 'median' agents, whose wealth is 4 times larger than for the impatient agents (computed for cohorts with multiplier of 1 for $\omega$ and $\phi$ ).

\subsection{Simulation scenarios}

The baseline scenario of no policy change involves the demographic and productivity change, see Section 3, but the pension system remains DB. In the reform scenario, the economy is in transition from a DB to a DC system. In the baseline and in the reform scenario we obtain wealth and consumption distributions for each point in time. In the reform scenarios, we introduce the two mechanisms designed to curb inequality: the minimum pension benefits and the lump-sum indexation.

\footnotetext{
${ }^{16}$ The budget constraint requires no debt at death, but permits negative savings throughout the life-cycle.
} 
Figure 2: Life cycle path of wealth accumulation (assets, $a_{j, k, 1}$ ) - initial steady state

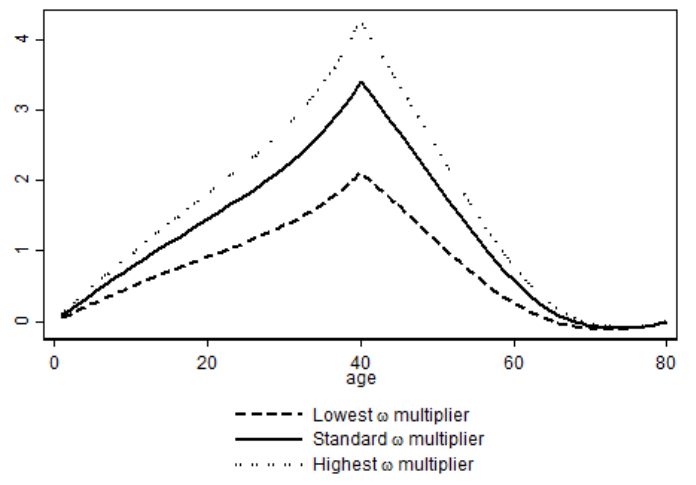

(a) different endowments, identical preferences

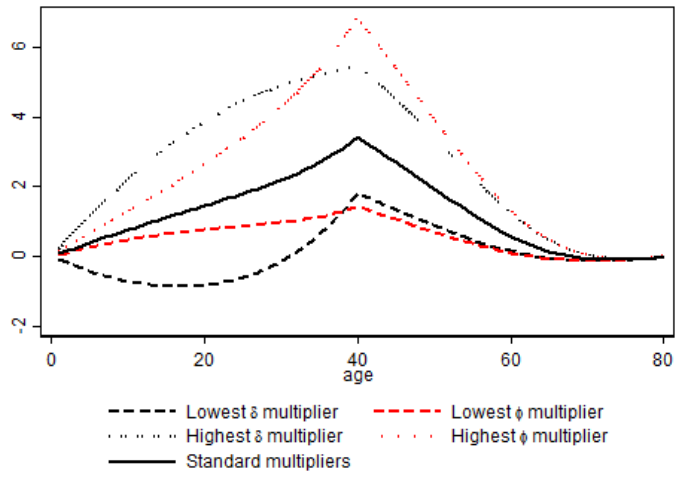

(b) identical endowments, different preferences

Figure 3: Life cycle path of labor supply $\left(l_{j, k, 1}\right)$ - initial steady state

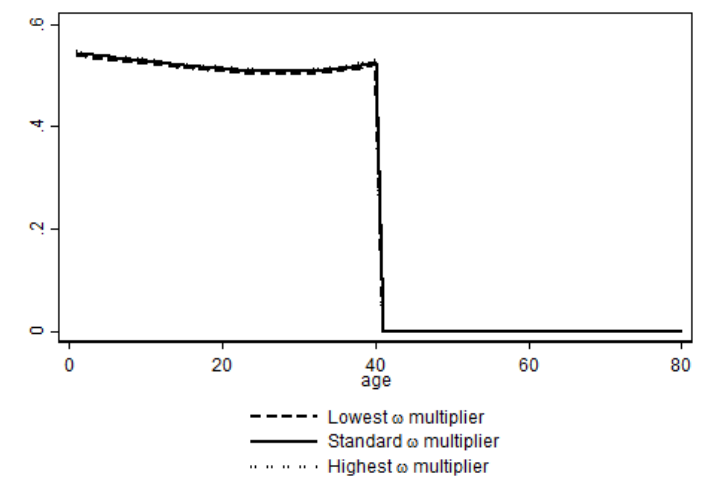

(a) different endowments, identical preferences

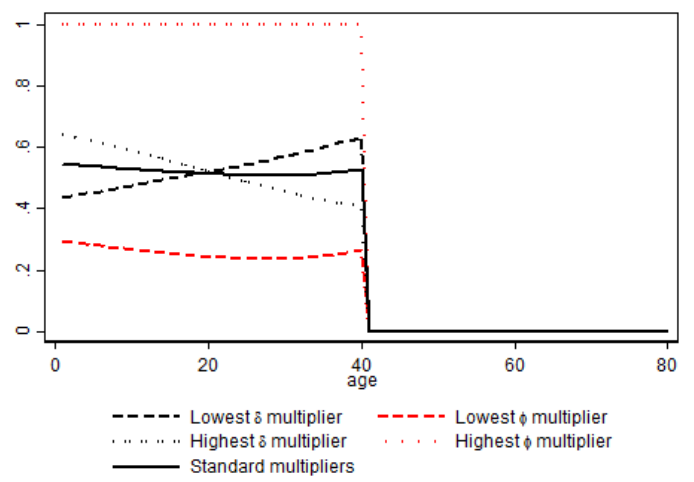

(b) identical endowments, different preferences

The minimum pension stipulates that an individual receives a minimum pension irrespectively of individual pre-retirement earnings. In the DB system that would imply that if $\rho \cdot w_{t-1} \cdot \omega_{k} \cdot l_{\bar{J}-1, k, t}$ falls short of the threshold $\underline{b}_{t}$, an individual receives $\underline{b}_{t}$ as the first pension benefit to be indexed in the next years for the surviving cohorts. In the DC system that would imply that if the combined annuity described in equation (11) falls short of $\underline{b}_{t}$, an individual receives $\underline{b}_{t}$ as the first pension to be indexed in the next years for the surviving cohorts.

The value of $\underline{b}_{t}$ has been computed from actual values, as a share of wage income in $t=1$ and kept at the same ratio for the subsequent periods. Note that this instrument automatically redistributes towards low productivity and high leisure preference subcohorts. Since in principle pure DC systems are balanced, this redistribution necessitates taxation surge. Namely, paying out pensions in excess of accumulated savings to some subcohorts will generate a gap in the pension system. Following the assumed government budget constraint, this will imply an increase in consumption taxes in our setup, relative to the scenario of no minimum pensions. Notably, this increase in taxes may be lower than in the baseline scenario of DB pension system, which in general are not balanced.

In 1999, according to the data published by Social Insurance Fund, about $4 \%$ of the 
retirees collected a minimum pension benefit. Our calibration of endowments and preferences replicate these features. However, longevity as well as a change in the pension system (from a defined benefit to a defined contribution) may affect these proportions, because longer period of retirement implies lower pensions under DC, ceteris paribus. Figure A1 in the Appendix displays the changes in the coverage by the minimum pension for the transition from the defined benefit pension system to the defined contribution one. The demographic transition necessitates substantial adjustment in the coverage rate for the DC system. In fact, the coverage rate increases from about $4 \%$ to as much as nearly $80 \%$ in the final steady state. This implies that the forced savings in the obligatory pension system are not sufficient to provide for the old age security. Please note, that the life expectancy increases in our simulations by 9 years in total, but we keep the retirement age constant, thus isolating the effect of minimum pensions. Despite this increase in the coverage of the minimum pension benefits, the necessary increase in taxes under DC system is much lower than the one forseen for the DB system.

The second instrument, lump sum indexation, stipulates that the total funding for indexation in a given year is spread equally among all pension benefit recipients. Following the left hand side of equation (9), the total growth in pensions between year $t$ and year $t+1$ is given by the demographic change (some cohorts dying and a new cohort becoming pension benefit recipients) and the indexation given by equation (10). Hence, the relative growth in pension benefits is higher for low-pension benefit recipients than in the proportional indexation case. By the same token, high income earners throughout working period receive less than proportional pension benefit increase. This instrument requires no calibration. It also remains fiscally neutral in a sense that the total pension expenditure remains intact (there may naturally be some general equilibrium effects).

\section{Results}

The overall feature of perfect foresight models is that agents adjust savings to the expected path of future incomes. This implies that longevity translates to increased savings and thus assets regardless of the pension system, although the reasons differ. Under the defined benefit system, agents expect a stark increase in taxation, which lowers their net income. In the defined contribution scheme agents expecting to live longer need higher savings to supplement the relatively low pension benefits. Consequently, there are likely to be substantial effects of the longevity on wealth inequality. ${ }^{17}$ We also expect the instruments to affect inter-temporal choice of agents. By contrast, the effects for consumption inequality should be smaller, because here the effects are less direct, occurring via possibly differently smoothed consumption and via changes in the labor supply.

\subsection{Aggregate inequality}

In the DB system, the wealth inequality is substantially larger during the demographic transition, to level off once the new population structure stabilizes, see Figure 4a. The transition to a

\footnotetext{
${ }^{17}$ Wealth inequality is measured as inequality of assets. For brevity, henceforth we use the term wealth inequality rather than inequality of assets.
} 
defined contribution system necessitates adjustments in individual voluntary savings, leading to a starker increase in consumption inequality, but less wealth inequality (mostly due to a lower fraction of subcohorts with negative savings).

The minimum pension benefit reduces consumption inequality permanently, by roughly $50 \%$ of the original increase due to the pension system reform from DB to DC. By analogy, the decline in wealth inequality is substantially weaker. This suggest that the incentives from the minimum pension are rather strong, lowering the individual voluntary savings, and thus slowing down the rate of capital accumulation, permanently. However, wealth inequality is lower with DC system than in the case of the DB system, which suggests that impatient subcohorts increase savings more in response to demographic changes under a DC system than in the case of a DB system. This effect stems from lower expected pension benefits under the DC system. The deterrence from private savings is confirmed in Figure $4 \mathrm{~b}$, with inequality measures at retirement (for subsequent cohorts reaching that age). The majority of the effect on consumption inequality comes from the demographic transition (changes in life expectancy), whereas the majority of the effect on wealth inequality comes from the pension system reform and may be largely influenced by minimum pension benefits

By contrast, the lump sum indexation has virtually no effect on inequality of either consumption or wealth. Although this instrument redistributes within cohort after retirement, the scope of inequality accumulated until retirement cannot be visibly influenced by an instrument of such small scope. While many countries consider it as a viable way to reduce old age poverty, the effect of lump sum indexation on poverty is negligible even if one analyzes only poverty among the retirees, as portrayed by Figure 4c. Clearly, minimum pension benefits reduce poverty and old age poverty, relative to the transition to DC system with no redistribution. This result is a flip side of lower incentives for private voluntary savings among the individuals with lower life-time income profiles.

The results for the Gini coefficient are reflected in other inequality measures, see Figure 5. For brevity, we present the synthetic comparison of the distributional and dispersion measures for selected years of the transition (left axis denotes measures of inequality for consumption, full bars and right axis denotes measures of inequality for wealth, empty bars). ${ }^{18}$ While the introduction of the DC system leaves older cohorts with less room to adjust to the new rules, gradually the difference in the consumption Gini coefficient decreases to stabilize with the new demographic structure. However, wealth inequality diverges between DB and DC systems. The instrument with the strongest power to reduce consumption inequality and at the same time increase wealth inequality is the minimum pension. In fact, given the wide coverage of the minimum pension, wealth inequality is substantially higher with the minimum pension benefit than with no instrument. The majority of this effects for wealth inequality appears to stem from the lower part of the wealth distribution, whereas for consumption inequality the effects are the largest at the top part of the distribution.

Our results could be related to recent findings by Buyse et al. (2017) who examine the impact of pension system schemes on macroeconomic and welfare effects in an economy with endogenous human capital accumulation and individuals differing ex ante with respect to their

\footnotetext{
${ }^{18}$ The complete set of measures for all periods and across all methods is available at [LINK].
} 
Figure 4: Evolution of Gini coefficients and poverty, all subcohorts

(a) Gini coefficient, all subcohorts, left: consumption, right: wealth
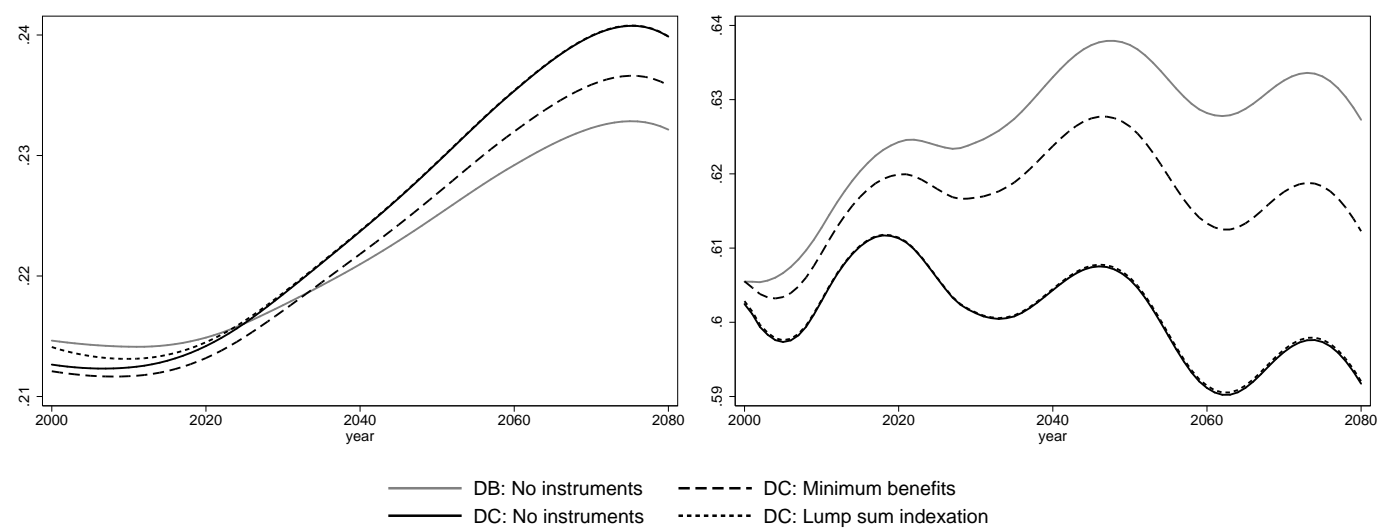

(b) Gini coefficient, at retirement, left: consumption, right: wealth
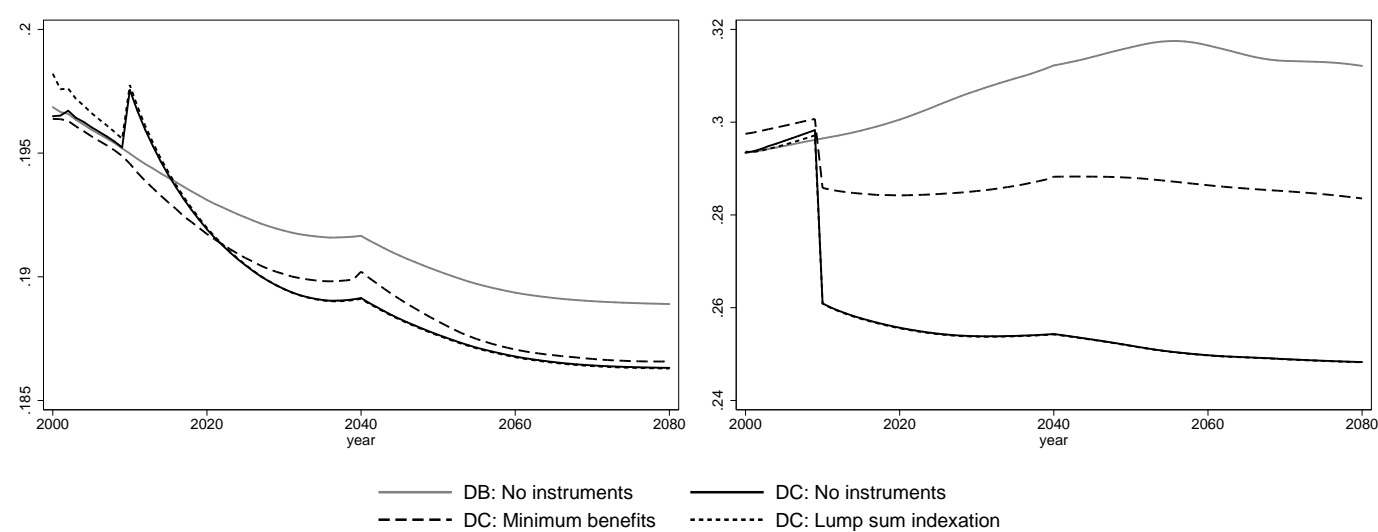

(c) poverty, left: share of population below poverty line, right: share of retirees below poverty line
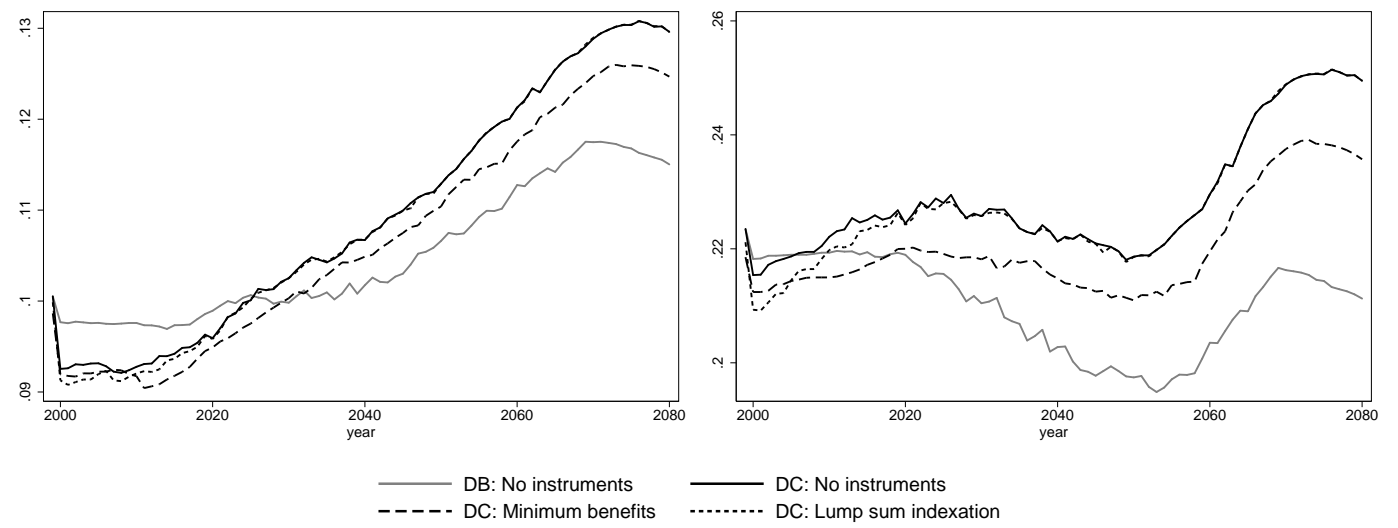

Note: Poverty line threshold established as consumption below 50\% of the median consumption. 
Figure 5: Evolution of inequality measures over time

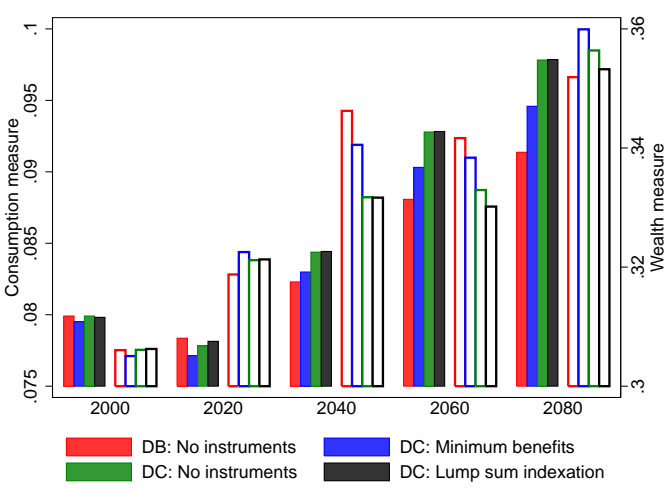

(a) Theil index

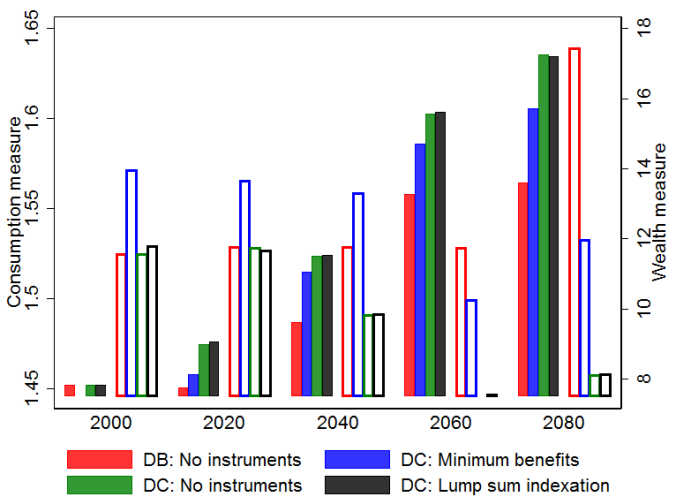

(c) 50-20 percentile

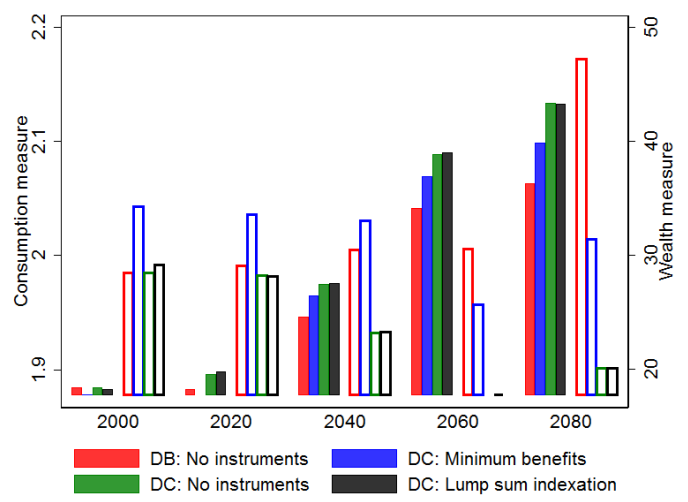

(b) 80-20 percentile

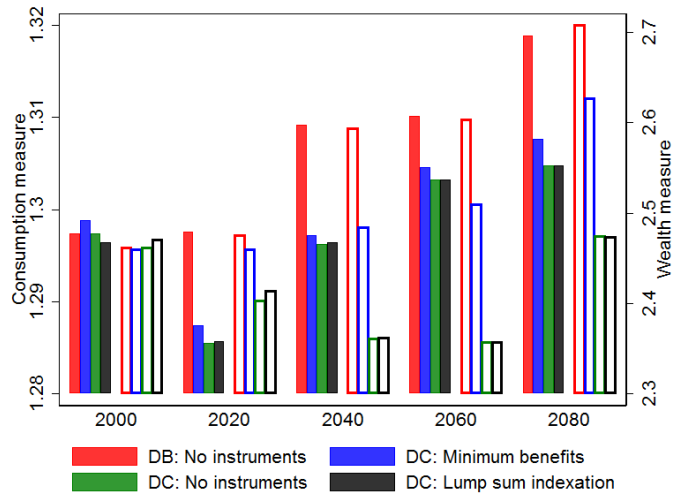

(d) 80-50 percentile

Note: left axis denotes measures of inequality for consumption, full bars and right axis denotes measures of inequality for wealth, empty bars. 
human capital accumulation ability. In their setup, labor supply of lowest ability individuals drops sharply in DB with minimum pensions relative to pure DB system, whereas we argue that the labor supply disincentives are small relative to other effects observed in the economy subsequent the introduction of the minimum pensions. However, Buyse et al. (2017) analyze minimum pensions in DB system, whereas we do it in a DC system. In our specification in a DB system a minimum pension guarantee would affect only a small fraction of the entire population, as the Polish DB system was very generous in terms of high replacement rates. Moreover, there appear to be substantial differences in calibration: where our utility function implies Frisch elasticity of about 1, their specification implies a negative Frisch elasticity equal to $-1 / 2$. Finally, in their setup, agents optimize labor supply and investment in human capital, which is a different optimization problem than the one Buyse et al. (2017) put forward. ${ }^{19}$

\subsection{Macroeconomic effects}

Although wealth inequality grows, the aggregate effect on capital is negligible. The fiscal consequences are considerable, though. Overall, the fiscal cost of unchanged pension system (DB) under demographic transition is substantial, requiring an almost twofold increase in consumption taxes by year 2080. In principle, pure DC system is balanced, so by the year 2080 there is no deficit in the pension system. Also, tax rates can be somewhat lowered once DC is implemented. Clearly, minimum pensions under a DC system are quite costly from a fiscal perspective, however the fiscal cost is much smaller than under the DB system. Lump sum indexation, due to fiscal neutrality and very modest scope of redistribution has almost no macroeconomic effects compared to the pure DC system.

Table 1: Macroeconomic effects (until $t=2080$ )

\begin{tabular}{l|cc|c|c}
\hline \hline & \multicolumn{2}{|c|}{ No instrument } & DC with minimum & $\begin{array}{c}\text { DC with lump sum } \\
\text { benefits }\end{array}$ \\
\hline Capital & $184 \%$ & $197 \%$ & $193 \%$ & $197 \%$ \\
\hline \multicolumn{7}{c}{ Tax rates } \\
\hline initial steady state & 11.00 & 11.00 & 11.00 & 11.00 \\
$t=2080$ & 20.50 & 10.97 & 14.21 & 10.95 \\
\hline \multicolumn{7}{c}{ Pension system deficit } \\
\hline initial steady state & 0.56 & & 2.52 & -0.18 \\
$t=2080$ & 7.06 & -0.14 & DC
\end{tabular}

Notes: Capital reported in relation to the initial steady state (ratio, in \%), expressed per effective unit of labor. Pension system deficit as a share of GDP, negative numbers indicate surplus. DC denotes transition from DB to DC. The values for the final steady state are reported in Table A2 in the Appendix.

\footnotetext{
${ }^{19}$ Indeed, they find that while an introduction of a fully funded DC system increases labor supply and effective retirement age for all ability groups, it has negative impact on human capital formation relative to a DB system. This result is in line with the result by Kindermann (2015) that DB systems subsidize human capital formation relative to DC systems, as the implicit tax structure in DB systems favors earnings paths with high slope (corresponding to high human capital formation) relative to flat earnings paths (corresponding to low human capital formation).
} 


\subsection{Welfare effects}

We display welfare effects as a comparison of individual utilities in the world with an instrument to those from the world where there are no instruments. Hence, the 'baseline' for welfare comparisons is the transition from DB to DC with no instruments, whereas 'reform' for welfare comparisons is transition with minimum pension benefits or transition with lump sum indexation. We measure change in utility as compensating variation and express it in terms of per cent of lifetime consumption discounted to $j=1$. To obtain the aggregate compensating variation we sum (with appropriate weights) over the lump sum transfers needed to maintain subcohorts' lifetime utility at unchanged level and express it relative to the aggregate lifetime consumption of the entire cohort in a year when this cohort comes to the model. The aggregate welfare effects are displayed in Figure 6. Figure 7 shows the welfare effects by subcohorts entering the model in year 2040. We pick this cohort, since it arrives in the model after the transition is effectively over, hence the welfare effect stems largely from the difference in the pension system arrangements.

As displayed in Figure 6, effects of lump sum indexation are low, but minimum pension benefits actually yields large positive effects. Figure 7 reveals that the positive effects arise predominantly from individuals with low productivity endowment. The only group that loses on the introduction of the minimum pension benefits are agents characterized by low preference for leisure and high impatience: the gains from possibly higher pension benefits in the old age weigh insufficiently in their utility function, relative to higher cost of consumption due to a high fiscal cost of implementing this instrument. In the case of lump sum indexation, agents with low preference for leisure observe welfare loss, due to relatively worse relationship between hours worked and pension benefits (higher implicit taxation of labor). Especially patient agents, who allocate high weight to future pension benefits, but also contribute to the pension system due to high labor supply observe welfare losses. However, welfare effects of lump sum indexation are one order of magnitude smaller than those of minimum pension benefits.

Summarizing, there are considerable wealth and consumption consequences of introducing minimum pension benefits. If consumption equality was the policy objective, this instrument helps to achieve it in the defined contribution system, but at the expense of fostering wealth inequality. Additionally, there are high fiscal cost in the form of pension system deficit and thus higher taxes to all cohorts. Overall, welfare effects of minimum pensions are large. Lump sum indexation has negligible effect on inequality, old-age poverty and thus also welfare.

These overall results help build an intuition on the effects introduced by two instruments: minimum pension benefit and lump sum indexation. At this point, however, we are unable to judge if these effects - especially in the case of minimum pension - stem from large response to the instrument or rather from the heterogeneity of agents combined with the demographic transition. To put it differently, are minimum pension benefits overcoming the dispersion in endowments? Or maybe the extent of redistribution exceeds these objective sources of heterogeneity and also dispersion in preferences is counteracted? In the next section we separate these two effects. Since effects for lump sum indexation are negligible, in the interest of brevity, we focus on the minimum pensions. 
Figure 6: Aggregate welfare effects

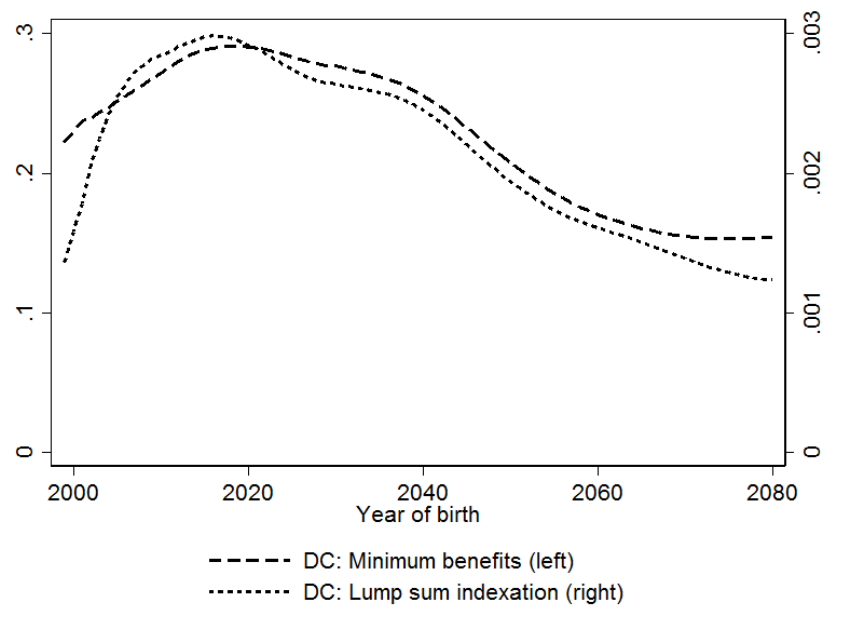

Figure 7: Disaggregated welfare effects, by subcohort, cohort born in $t=2040$

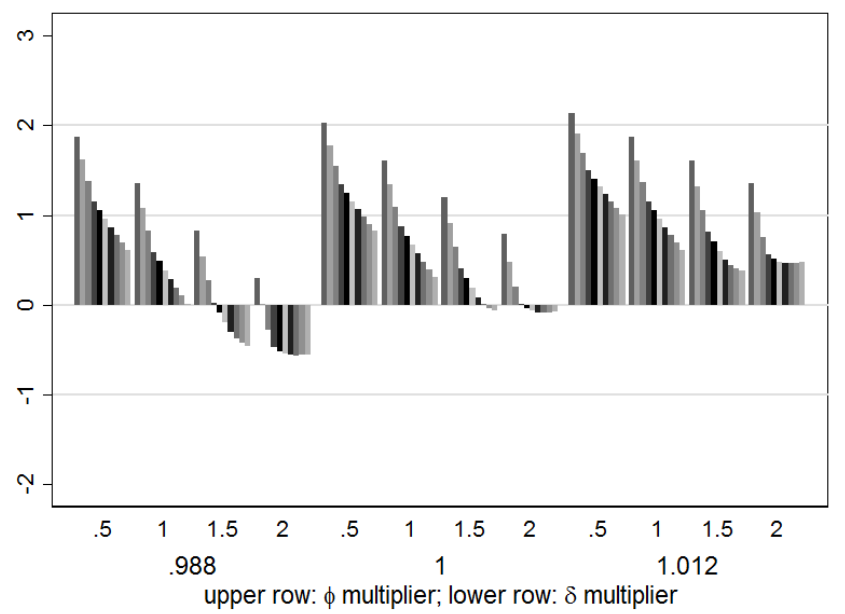

(a) minimum benefits

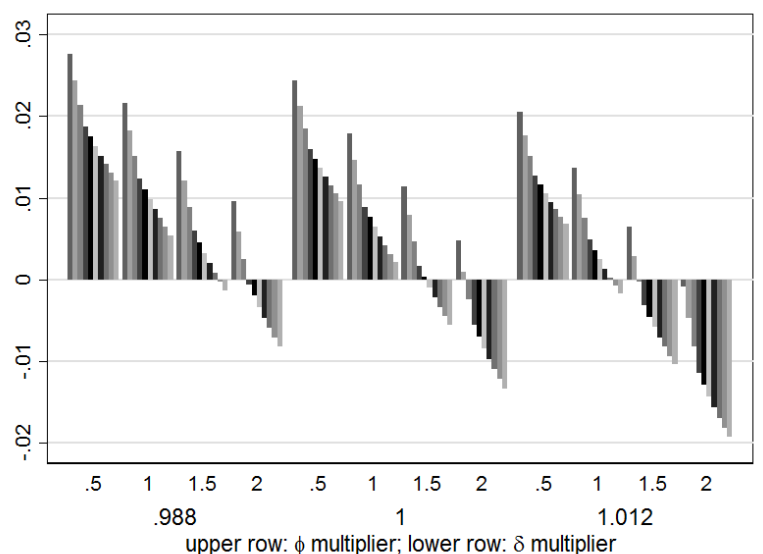

(b) lump sum indexation

Note: Bars ordered following the values of $\omega$, with the least productive individuals most to the left in each panel. Full set of results for each birth cohort available at [LINK]. Cohort born in $t=2040$ lives all their lifes after the transition 29 rom DB to DC is completed in a sense that all pensions from the old pension system are already terminated. 


\section{Identifying channels for changes in inequality}

To identify whether redistribution addresses the inequality which stems from dispersion of endowments or rather inequality which stems from differentiated preferences, we propose the following experiment. In a partial equilibrium setup (i.e. keeping the prices intact) we eliminate one of the channels of heterogeneity and recalculate the equilibrium for all the paths: the DB system, the transition to DC system with no instruments and the transition to DC system with minimum pension benefits. We can subsequently compute the inequality measures for those implied new paths (keeping prices fixed at levels from a respective path with all channels of heterogeneity on partial equilibrium). We depict the results of this analysis for Gini coefficient and share measures in Figure 8, whereas other measures of inequality are deferred to the Appendix (see Figure A3). Solid and dashed thick lines plot the level of inequality measure in the scenario of transition to DC with no instruments and the scenario of transition to DC with minimum pension benefit, respectively. Thin dashed black and gray lines depict the relative (percentage) difference between these two scenarios and a reform to DC scenario, under partial equilibrium with only one dimension of heterogeneity: either preference heterogeneity (dashed black line) or endowment heterogeneity (dashed gray line).

When we eliminate any dispersion in endowments, the measures of inequality are fairly similar across scenarios - dashed thin black line hovers in the vicinity of zero. However, eliminating the heterogeneity of preferences implies a substantial decrease in consumption inequality. This conclusion is robust to the way inequality is measured. For wealth inequality, both preferences and endowments channels appear to have effects of similar magnitude on the reduction of the aggregate inequality due to minimum pension benefits. ${ }^{20}$ However, the preference channel is much stronger at the bottom of the wealth distribution.

Although the majority of changes in inequality stems from the demographic transition, the instruments tend to reduce inequality more in the case of a simulation without preference heterogeneity than in the case of a simulation with no endowments heterogeneity. Consequently, the effects are bigger for what could be called "equality of opportunity". Notably, inequality which stems from heterogeneity of preferences is a large part of overall inequality, whreas inequality which stems from heterogeneity of endowments is a small part of overall inequality. Table A3 in the Appendix demonstrates that if we switch off the heterogeneity in endowments, all of the inequality indicators are roughly of similar order of magnitude to overall inequality, whereas if we switch off heterogeneity in preferences, inequality is substantially lower. Since minimum pension benefit operates mostly along the channel which contributes a relatively less to overall inequality, then clearly the scope for reducing inequality is also constrained.

\section{Discussion and conclusions}

Inequality in income and wealth during the working period translate to inequality in consumption during the retirement. Many countries employ policy instruments with the aim to provide redistribution within the pension system. The rationale behind such solutions are

\footnotetext{
${ }^{20}$ The reason why wealth inequality increases under minimum benefits scenario despite the partial equilibrium effects point in the other direction is due to strong general equilibrium effects.
} 
Figure 8: Sources of changes in inequality due to the minimum pension benefits

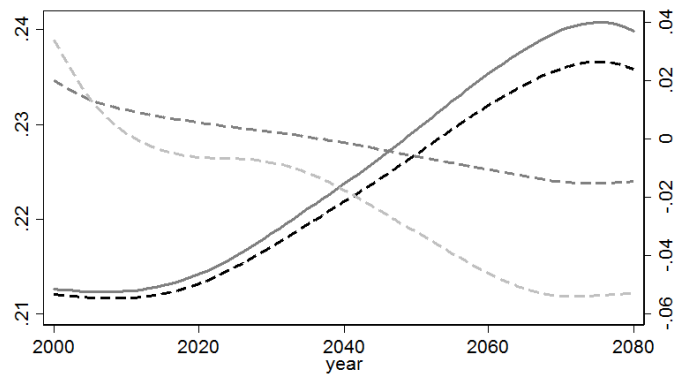

DC: No instruments

--.-. DC: Minimum benefits

- - - - Influence on the preferences margin (right)

---- Influence on the endowments margin (right)

(a) Gini coefficient

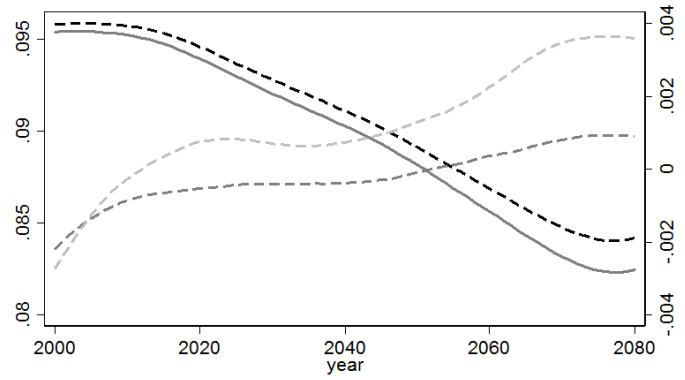

DC: No instruments

- - - - - Influence on the preferences margin (right)

Influence on the endowments margin (right)

(c) share of bottom $20 \%$

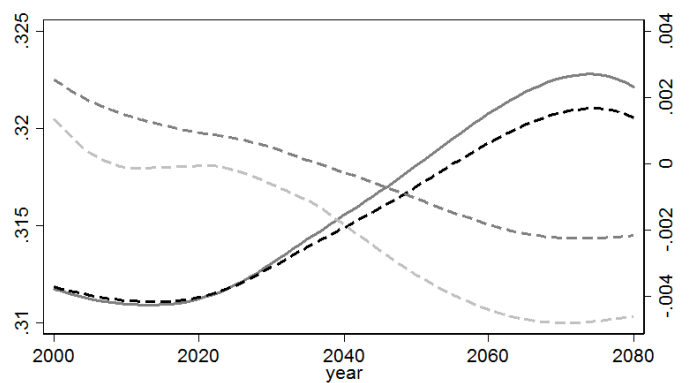

DC: No instruments

----- DC: Minimum benefits

---- Influence on the preferences margin (right)

influence on the endowments margin (right)

(e) share of top $20 \%$

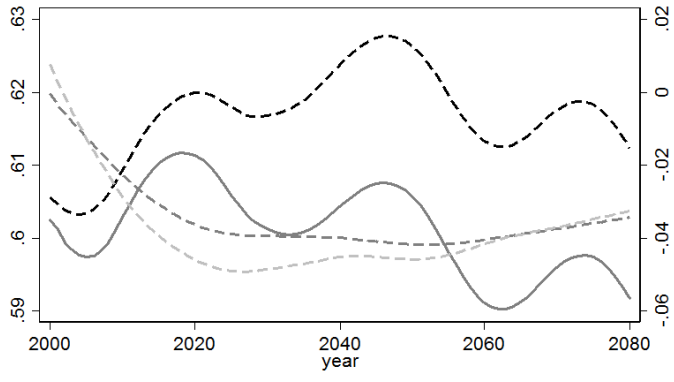

DC: No instruments

---.- DC: Minimum benefits

- - - - Influence on the preferences margin (right)

--..-- Influence on the endowments margin (right)

(b) Wealth inequality

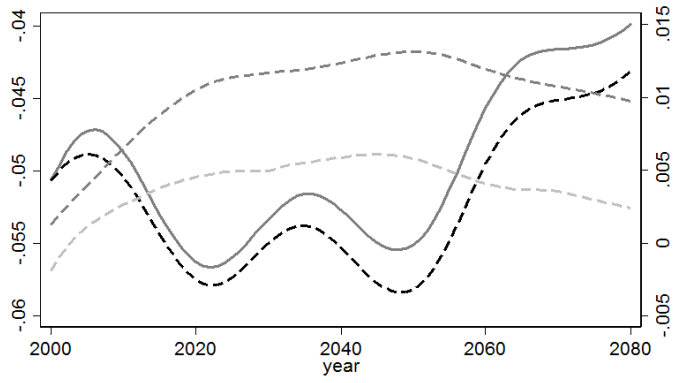

DC: No instruments

- - - Influence on the preferences margin (right) Influence on the endowments margin (right)

(d) Wealth bottom 20

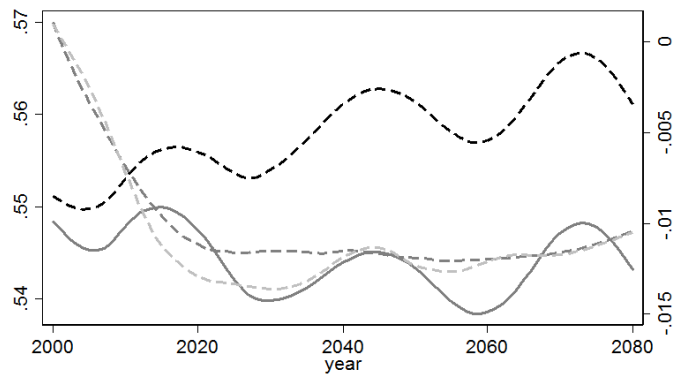

\begin{tabular}{l} 
DC: No instruments \\
\hline-- DC: Minimum benefits \\
--- Influence on the preferences margin (right)
\end{tabular}

(f) Wealth top 20

Note: Solid and dashed thick lines plot the level of inequality measure in the scenario of transition to DC with no instruments and the scenario of transition to DC with minimum pension benefit, respectively. Dashed gray and light gray lines depict the relative (percentage) difference between these two scenarios and a reform to DC scenario under partial equilibrium with only one dimension of heterogeneity: either preference heterogeneity (dashed black line) or endowment heterogeneity (dashed gray line). 
both pragmatic (if redistribution was not rooted in the pension system, it would have to be accounted for in general social benefits) and value based (misfortune during the working period - e.g. prolonged spells of non-employment - should not necessitate poverty when one is no longer able to work). In theoretical models and simulations the pragmatic reasoning is equivalent to a minimum pension benefit nested in the system. Effects of introducing such instruments have previously been evaluated empirically. The main contributions of this paper are twofold. First, we analyze the projected effects of increases in longevity and pension system reform on inequality of consumption and wealth towards the future. Second, we decompose the inequality into inequality that comes from objective dispersion in skills and abilities (which we operationalize as heterogeneity of endowments) and inequality that stems from preferences.

Our overlapping generations framework allows to compare two types of pension systems: defined contribution and defined benefit. We account for changing demographics as well as gradually decreasing rate of the technological progress. We nest in the model two instruments which are popular policy solutions: minimum pension guarantee and lump sum indexation. We supplement the standard overlapping generations model with a within-cohort heterogeneity. While some of the previous studies allowed for differences in endowments, our setting allows agents to differ also in terms of time preference as well as leisure preference.

In general, redistribution within the pension system is intended to address not only low earners, but also high earners. For example, the rationale behind the lump sum indexation is typically that paying out (extremely) high pension benefits to (extremely) highly productive individuals in a general, obligatory pension system is politically non-viable and economically redundant, because these individuals will be able to smoothen life-time consumption with private savings. This contention depends on a presumption that high productivity goes together with preference for future consumption as well as preference for work. In our framework the distribution of endowments is independent from a distribution of preferences: some of the low productivity individuals have high preference for work and high propensity to save for future consumption. Admittedly, there is little empirical research so far on how the preferences and endowments correlate across societies. Our setup is calibrated to replicate the aggregate and distributional features of the Polish economy. Following the data, the main driver of inequality is heterogeneity of preferences, with a smaller role for the dispersion of endowments.

We find that increasing longevity is the big force behind changes in wealth and consumption inequality. The increase in consumption inequality in the baseline scenario of a defined benefit pension system amounts to over $10 \%$ of the Gini coefficient on consumption inequality. Also wealth inequality increases with increasing longevity in the DB system (agents with low consumption profiles expect to receive relatively generous pension benefits, hence see little reasons to save, whereas individuals with high consumption profiles, expecting consumption tax surge to cover the deficit in the pension system, make precautionary savings). The pension system reform introduces two major changes in agents' choices. First, they expect lower pension benefits and lower consumption taxes with the implementation of the reform. Second, they start seeing the link between labor supply and future pension benefits, which implies decline in labor taxation as well. These incentives result in higher labor supply and higher voluntary private savings. Such raises the consumption inequality and reduces the wealth inequality. Growth in consumption inequality is lower than that observed due to longevity. 
On this setup we experiment with two instruments that are typically considered as means to reducing inequality, especially old-age inequality. These are minimum pension benefits and lump sum indexation. The effects of lump sum indexation are negligible, as this instrument is too weak to affect choices of agents and distribution of consumption among the retirees. Minimum pension benefits are very effective in reducing old-age and overall consumption inequality. They also contribute to higher wealth inequality, as they eliminate part of the precautionary motive. For a policymaker concerned with consumption equality rather than wealth equality these effects are noticeable. The reduction of inequality comes with positive overall welfare effects, but at the expense of high fiscal cost. Analyzing the channels through which these changes occur we find that this instrument could be particularly effective towards overcoming the inequality of opportunity.

The strong response of wealth inequality to changes in longevity stems in our model from the fact that agents are rational and have perfect foresight: expecting longer lives (and in some scenarios, also higher tax rates), they react with increased savings. The ability to save is heterogeneous along endowments as well as preferences, hence the initial inequality in wealth is amplified. Agents increase savings by altering their inter-temporal choices, which attenuates the initial inequality of consumption. If and to what extent people react to the longer life expectancy remains an area of active research and while the magnitude of response by some subcohorts may appear as relatively high, there is compelling evidence that over the past two decades we have witnessed an increase in wealth inequality and increase in life expectancy in most industrialized countries.

The result that minimum pension benefit operates mostly along the endowments margin implies that the behavioral response to guaranteed income in the old age stems from little or no response in terms of labor supply. Partly, it is a consequence of the assumption about the shape of the utility function. With log-linear intra-temporal preferences, income and substitution effects tend to cancel out, which attenuates any changes in individual labor supply. Whether such assumption about the shape of the utility function is plausible remains an area of empirical research. Gruber (2000) argues in favor of substantial labor supply elasticity to the value of benefits, but these estimates were put in question in subsequent studies (e.g. Campolieti 2004). Estimates from other countries - e.g. Austria (Mullen and Staubli 2016) - cannot be compared directly to our setup. Such estimates analyze a sudden, unexpected policy change and measure the effect for the directly affected cohorts. In our setup, the minimum pension benefits are negligible for the older cohorts, because these remain still in the DB system, with relatively high pension benefits. Hence, effectively the instrument operates with delay (even if introduced unexpectedly). An alternative to log-linear preferences is to assume Greenwood et al. (1988), which relate labor supply directly to changes of wage rate. However, in a recent study, Bielecki et al. (2015) demonstrate that in the context of OLG the shape of the utility function has much less of a role in determining the labor supply reaction, as the key element is making agents account for pension benefits in the labor supply decisions, which our setup does.

Another part of the reason on why the labor supply does not react substantially to the introduction of minimum pensions stems exactly from the fact that agents see the link between (instantaneous) labor supply and pension benefits. With the time (and thus progress of longevity), a vast majority of agents receives pension benefits no higher than minimum pensions. 
However, even if they cannot influence their future pension benefit through increasing labor supply, they still react to the usual incentives. In particular, agents receive no income support instruments throughout the working period, and they need to work in order to provide for their current consumption.

Importantly, the result that the minimum pension benefits operate along the "equality of opportunity" channel does not mean that our setup eliminates the potential disincentives for labor supply among agents with stronger preference for leisure. Our setup makes agents internalize the minimum pension benefits (and lump sum indexation) in the entire lifetime labor supply. This internalization - that agents are forward looking - implies that an agent knows already in $j=1$, from knowing her type $k$ and prices, that she will or will not receive a minimum pension as of $j=\bar{J}$. Hence, agents internalize potential disincentives from unconditional transfer from $j=1$. Rather the shape of the utility function implies that the response is smooth and low.

Our results could be related to recent findings by Buyse et al. (2017) who examine the impact of pension system schemes on macroeconomic and welfare effects in an economy with endogenous human capital accumulation and individuals differing ex ante with respect to their human capital accumulation ability. In their setup, labor supply of lowest ability individuals drops sharply in DB with minimum pensions relative to pure DB system, whereas we argue that the labor supply disincentives are small relative to other effects observed in the economy subsequent the introduction of the minimum pensions. However, Buyse et al. (2017) analyze minimum pensions in DB system, whereas we do it in a DC system. In our specification in a DB system a minimum pension guarantee would affect only a small fraction of the entire population, as the Polish DB system was very generous in terms of high replacement rates. Moreover, there appear to be substantial differences in calibration: where our utility function implies Frisch elasticity of about 1.3, their specification implies a negative Frisch elasticity equal to $-1 / 2$. Finally, in their setup, agents optimize labor supply and investment in human capital, which is a different optimization problem than the one Buyse et al. (2017) put forward. ${ }^{21}$

The theoretical predictions within the scope of this study are relatively scarce which makes our finding valuable from a policy perspective. First, based on theoretical premises, under increasing longevity a reform to a DC system results in higher consumption inequality between cohorts than a DB system. This owes to the fact that DC system yields substantially lower pension benefits (hence old generations have substantially lower incomes under DC than under DB, increasing consumption inequality measured in cross-section). However, it is theoretically ambiguous if it results in higher wealth and consumption inequality within cohort, either preor post-retirement. We show that the biggest force behind changing the aggregate inequality is the longevity and changing population structure - in fact the shift in inequality due to the pension system reform is minor. Second, in theory, an optimal response to a minimum pension benefit guarantee is to lower the lifetime savings as well as the labor supply. Thus,

\footnotetext{
${ }^{21}$ Indeed, they find that while an introduction of a fully funded DC system increases labor supply and effective retirement age for all ability groups, it has negative impact on human capital formation relative to a DB system. This result is in line with the result by Kindermann (2015) that DB systems subsidize human capital formation relative to DC systems, as the implicit tax structure in DB systems favors earnings paths with high slope (corresponding to high human capital formation) relative to flat earnings paths (corresponding to low human capital formation).
} 
unless substitution effect is very strong, one should should expect lower consumption inequality post-retirement. However, the effect on pre-retirement consumption will depend additionally on the general equilibrium effects. We find a large reduction in consumption inequality postretirement, but also aggregate (along with an increase in wealth inequality, both aggregate and post-retirement). Importantly, we find virtually no negative effect on aggregate savings. Minimum pension guarantee actually cuts in half the increase in consumption inequality due to the pension system reform, though at a considerable fiscal cost. Third, a way to reduce the fiscal costs of post-retirement redistribution of incomes is the lump sum indexation. In principle, this instrument breaks the link between contributions and future pensions, possibly providing labor supply disincentives for both high and low earners (although for different reasons: low earners receive more benefits whereas high earners experience higher implied taxation). We show that the effect of such a instrument is negligible - inequality remains unaffected by this fiscally neutral solution. Fourth and final, one should expect particularly large strategic response to introducing the minimum pension benefit - e.g. high preference for leisure should translate to much lower individual labor supply and savings if retirement income is guaranteed irrespectively of lifetime income. Thus, it is theoretically plausible that the minimum pension benefit guarantee will address mainly the inequality which stems from preferences. We find, however, that the feedback from future taxation dominates the free-riding incentives in the case of the preferences, hence the minimum pension benefits addresses mostly the inequality which stems from differentiated endowments and not that which stems from heterogeneous preferences.

Our findings provide intuitions which could be an interesting starting point for further research. For example, in our setup there is no social assistance benefits throughout the working life. This implies that agents - even low ability and high preference for leisure agents - have to work to finance instantaneous consumption. However, modern states provide a variety of income support instruments during the working periods (e.g. means-tested transfers), which may additionally influence the labor supply in the context of minimum pension benefits. Second, many countries introduce age and work experience eligibility criteria for minimum pension benefits. Policy experiments concerning the access to minimum pension benefits can reveal to what extent these two dimensions - value of minimum pension benefits and when it can be accessed - can alter the consumption and wealth distribution within societies. A third example concerns more sophisticated setups of the labor market. In our model labor is substitutable, which makes working agents gain from other agents leaving the market (through higher $\mathrm{K} / \mathrm{L}$ ratio). However, recent literature on how technology is changing capital-labor complementarity and how the process of automation affect inequality provides important insights on how making several types of labor complementary may affect the wealth and consumption distributions in an aging society. 


\section{References}

Axtell, R.: 2000, Why agents? On the varied motivations for agent computing in the social sciences, Center on Social and Economic Dynamics Working Paper 17, Center on Social and Economic Dynamics, The Brookings Institution.

Bassi, M.: 2008, An Egg Today and a Chicken Tomorrow: A Model of Social Security with Quasi-Hyperbolic Discounting, CSEF Working Papers 205, Centre for Studies in Economics and Finance (CSEF), University of Naples, Italy.

Benhabib, J., Bisin, A. and Luo, M.: 2015, Wealth Distribution and Social Mobility in the US: A Quantitative Approach, NBER Working Papers 21721, National Bureau of Economic Research, Inc.

Bielecki, M., Goraus, K., Hagemejer, J., Makarski, K. and Tyrowicz, J.: 2015, Small assumptions (can) have a large bearing: evaluating pension system reforms with OLG models, Economic Modelling 48, 210-221.

Börsch-Supan, A. and Weiss, M.: 2016, Productivity and age: Evidence from work teams at the assembly line, Journal of the Economics of Ageing 7, 30-42.

Bourguignon, F. and Spadaro, A.: 2006, Microsimulation as a tool for evaluating redistribution policies, Journal of Economic Inequality 4(1), 77-106.

Brzeziński, M.: 2012, Accounting for recent trends in absolute poverty in Poland: a decomposition analysis, Post-Communist Economies 24(4), 465-475.

Bucciol, A.: 2011, A Note On Social Security Welfare With Self-Control Problems, Macroeconomic Dynamics 15(04), 579-594.

Buyse, T., Heylen, F. and Van De Kerckhove, R.: 2017, Pension reform in an OLG model with heterogeneous abilities, Journal of Pension Economics and Finance 16(02), 144-172.

Campolieti, M.: 2004, Disability insurance benefits and labor supply: Some additional evidence, Journal of Labor Economics 22(4), 863-889.

Castañeda, A., Díaz-Giménez, J. and Ríos-Rull, J.-V.: 2003, Accounting for the U.S. Earnings and Wealth Inequality, Journal of Political Economy 111(4), 818-857.

Cremer, H. and Pestieau, P.: 2011, Myopia, redistribution and pensions, European Economic Review 55(2), 165-175.

Davies, J. B., Sandström, S., Shorrocks, A. and Wolff, E. N.: 2011, The Level and Distribution of Global Household Wealth, Economic Journal 121(551), 223-254.

De Nardi, M. and Yang, F.: 2016, Wealth inequality, family background, and estate taxation, Journal of Monetary Economics 77(C), 130-145.

Deaton, A.: 1997, The Analysis of Household Surveys: A Microeconometric Approach to Development Policy, World Bank Publications. 
Domeij, D. and Klein, P.: 2002, Public Pensions: To What Extent Do They Account for Swedish Wealth Inequality?, Review of Economic Dynamics 5(3), 503-534.

Fehr, H.: 2009, Computable Stochastic Equilibrium Models and Their Use in Pension- and Ageing Research, De Economist 157(4), 359-416.

Fehr, H., Habermann, C. and Kindermann, F.: 2008, Social Security with Rational and Hyperbolic Consumers, Review of Economic Dynamics 11(4), 884-903.

Fehr, H. and Kindermann, F.: 2010, Pension Funding and Individual Accounts in Economies with Life-cyclers and Myopes, CESifo Economic Studies 56(3), 404-443.

Fehr, H. and Uhde, J.: 2014, Means-testing and economic efficiency in pension design, Economic Modelling 44(S1), 57-67.

Feldstein, M.: 1995, Would Privatizing Social Security Raise Economic Welfare?, NBER Working Papers 5281, National Bureau of Economic Research, Inc.

Ferber, J.: 1999, Multi-agent Systems: An Introduction to Distributed Artificial Intelligence, Addison-Wesley.

Fleurbaey, M. and Maniquet, F.: 2005, Fair social orderings when agents have unequal production skills, Social Choice and Welfare 24(1), 93-127.

Fleurbaey, M. and Maniquet, F.: 2006, Fair Income Tax, Review of Economic Studies 73(1), 5583.

Gervais, M.: 2012, On the optimality of age-dependent taxes and the progressive U.S. tax system, Journal of Economic Dynamics and Control 36(4), 682-691.

Greenwood, J., Hercowitz, Z. and Huffman, G. W.: 1988, Investment, capacity utilization, and the real business cycle, The American Economic Review 78(3), 402-417.

Gruber, J.: 2000, Disability insurance benefits and labor supply, Journal of Political Economy 108(6), 1162-1183.

Gruber, J. and Wise, D. A.: 2004, Social Security Programs and Retirement around the World: Micro-Estimation, University of Chicago Press.

Hairault, J.-O. and Langot, F.: 2008, Inequality and social security reforms, Journal of Economic Dynamics and Control 32(2), 386-410.

Hénin, P.-Y. and Weitzenblum, T.: 2005, Welfare effects of alternative pension reforms: Assessing the transition costs for French socio-occupational groups, Journal of Pension Economics and Finance 4(03), 249-271.

İmrohoroğlu, A., İmrohoroğlu, S. and Joines, D. H.: 2003, Time-Inconsistent Preferences and Social Security, Quarterly Journal of Economics 118(2), 745-784. 
Kaganovich, M. and Zilcha, I.: 2012, Pay-as-you-go or funded social security? A general equilibrium comparison, Journal of Economic Dynamics and Control 36(4), 455-467.

Kanbur, R. and Stiglitz, J. E.: 2016, Dynastic inequality, mobility and equality of opportunity, Journal of Economic Inequality 14(4), 419-434.

Kindermann, F.: 2015, Earnings related pension schemes and human capital formation, Journal of Pension Economics and Finance 14(1), 19-54.

Kindermann, F. and Krueger, D.: 2014, High Marginal Tax Rates on the Top 1\%? Lessons from a Life Cycle Model with Idiosyncratic Income Risk, NBER Working Papers 20601, National Bureau of Economic Research, Inc.

Kirman, A.: 1997, The economy as an evolving network, Journal of Evolutionary Economics 7(4), 339-353.

Krusell, P. and Smith, A. A.: 1997, Income And Wealth Heterogeneity, Portfolio Choice, And Equilibrium Asset Returns, Macroeconomic Dynamics 1(02), 387-422.

Krusell, P. and Smith, A. A.: 1998, Income and Wealth Heterogeneity in the Macroeconomy, Journal of Political Economy 106(5), 867-896.

Kumru, C. S. and Thanopoulos, A. C.: 2011, Social security reform with self-control preferences, Journal of Public Economics 95(7), 886-899.

Lockwood, B. B. and Weinzierl, M.: 2015, De Gustibus non est Taxandum: Heterogeneity in preferences and optimal redistribution, Journal of Public Economics 124(C), 74-80.

McGrattan, E. R. and Prescott, E. C.: 2013, On Financing Retirement with an Aging Population, NBER Working Papers 18760, National Bureau of Economic Research, Inc.

Mullen, K. J. and Staubli, S.: 2016, Disability benefit generosity and labor force withdrawal, Journal of Public Economics 143, 49-63.

Nishiyama, S. and Smetters, K.: 2007, Does Social Security Privatization Produce Efficiency Gains?, Quarterly Journal of Economics 122(4), 1677-1719.

Russell, S. J. and Norvig, P.: 1995, Artificial Intelligence: A Modern Approach, Prentice Hall.

Song, Z.: 2011, The Dynamics of Inequality and Social Security in General Equilibrium, Review of Economic Dynamics 14(4), 613-635.

St-Amant, P.-A. B. and Garon, J.-D.: 2015, Optimal redistributive pensions and the cost of self-control, International Tax and Public Finance 22(5), 723-740.

Stigler, G. J. and Becker, G. S.: 1977, De Gustibus Non Est Disputandum, American Economic Review 67(2), 76-90.

Storesletten, K., Telmer, C. I. and Yaron, A.: 2004, Consumption and risk sharing over the life cycle, Journal of Monetary Economics 51(3), 609-633. 
Tesfatsion, L.: 2002, Agent-based computational economics: growing economies from the bottom up, Artificial Life 8(1), 55-82.

van de Ven, J. and Weale, M.: 2010, Modelling myopic responses to policy: an enhancement to the NIBAX model, DWP Working Paper 88.

Windrum, P., Fagiolo, G. and Moneta, A.: 2007, Empirical Validation of Agent-Based Models: Alternatives and Prospects, Journal of Artificial Societies and Social Simulation 10(2), 1-8.

Wooldridge, M.: 2009, An Introduction to MultiAgent Systems, John Wiley \& Sons.

Wooldridge, M. and Jennings, N. R.: 1995, Intelligent agents: Theory and practice, Knowledge Engineering Review 10(2), 115-152. 


\section{A Calibration}

Table A1: Calibrated parameters for the initial steady state

\begin{tabular}{|c|c|c|c|c|c|}
\hline \multicolumn{2}{|c|}{ Macroeconomic parameters } & \multirow{2}{*}{$\begin{array}{c}\text { Calibration } \\
0.500\end{array}$} & \multirow{2}{*}{$\begin{array}{c}\text { Target } \\
\text { employment ratio }\end{array}$} & \multirow{2}{*}{$\begin{array}{l}\text { Value } \\
56.8 \%\end{array}$} & \multirow{2}{*}{$\begin{array}{c}\text { Source } \\
\mathrm{NA}\end{array}$} \\
\hline$\phi_{k}$ & preference for leisure & & & & \\
\hline$\alpha$ & capital share & 0.310 & conventional value & & \\
\hline$\delta$ & discounting rate & 0.981 & interest rate & $7 \%$ & $(*)$ \\
\hline$d$ & depreciation rate & 0.043 & investment \% in GDP & $21 \%$ & NA \\
\hline$\tau_{l}$ & labor tax & 0.190 & revenue as $\%$ of GDP & $4.9 \%$ & OECD \\
\hline$\tau_{c}$ & consumption tax & 0.110 & revenue as $\%$ of GDP & $7.4 \%$ & OECD \\
\hline$\tau_{k}$ & capital tax & 0.190 & de iure & & \\
\hline$\rho$ & replacement rate & 0.280 & benefits as $\%$ of GDP & $5 \%$ & NA \\
\hline$\tau$ & social security contr. & 0.061 & deficit of pension sys. as $\%$ of GDP & $0.8 \%$ & NA \\
\hline$\underline{b}_{t}$ & minimum pensions & 0.065 & minimum pen. as $\%$ of all pensions & $4 \%$ & SIF \\
\hline
\end{tabular}

${ }^{*}$ ) this is the real effective net rate of return recorded by the private pension funds between 1999 and 2009. Pension funds were obliged by the law to hold a balanced portfolio. NA stands for National Accounts. SIF denotes Social Insurance Fund.

Figure A1: Coverage of the minimum pensions and fiscal adjustment

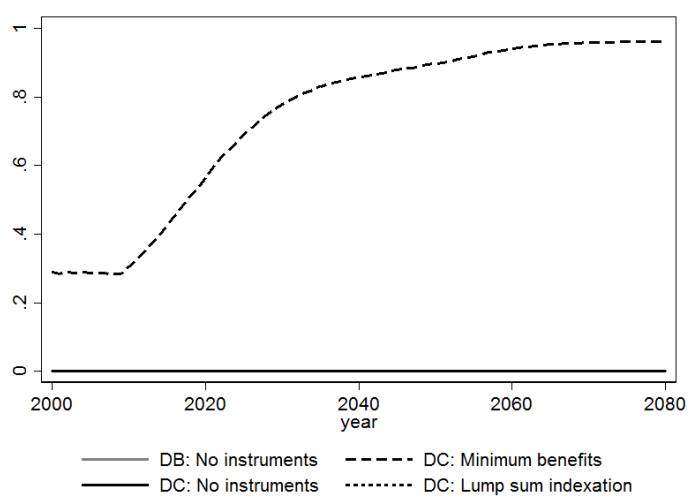

(a) minimum pension benefit coverage

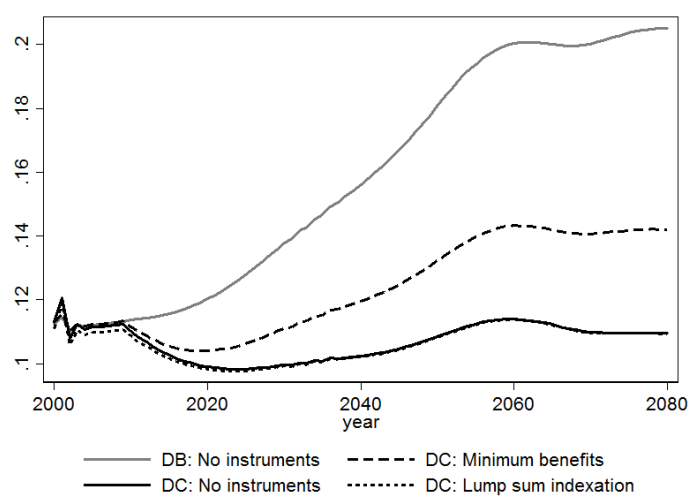

(b) consumption tax 


\section{B Appendix}

Table A2: Macroeconomic effects (the final steady state)

\begin{tabular}{l|cc|c|c}
\hline \hline & \multicolumn{2}{|c|}{ No instrument } & DC with minimum & DC with lump sum \\
DB & DC & benefits & $187 \%$ \\
\hline \hline Capital & $177 \%$ & $187 \%$ & $184 \%$ & 11.00 \\
\hline & \multicolumn{4}{|c}{ Tax rate } \\
\hline initial steady state & 11.00 & 11.00 & 11.00 & 10.15 \\
final steady state & 16.70 & 10.17 & 12.06 & -0.80 \\
\hline & \multicolumn{5}{|c}{ Pension system deficit } \\
\hline initial steady state & 0.56 & 0.81 & 0.76 \\
final steady state & 4.00 & -0.76 & .
\end{tabular}

Notes: Capital reported in relation to the initial steady state (ratio, in \%), expressed per effective unit of labor. Pension system deficit as a share of GDP, negative numbers indicate surplus. DC denotes transition from DB to DC.

Figure A2: Macroeconomic effects of instruments

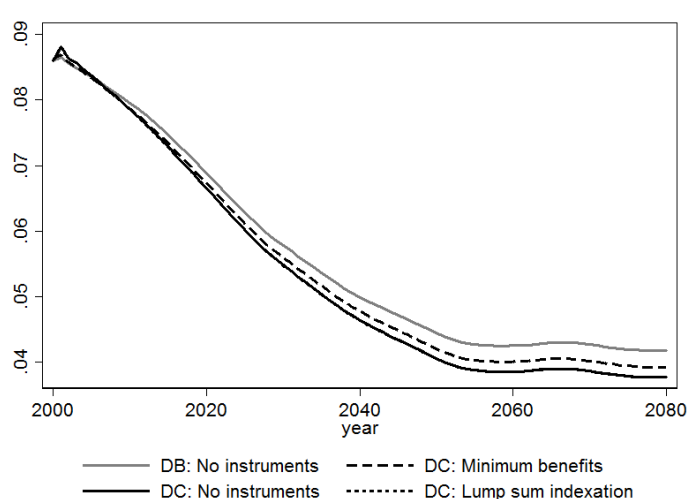

(a) interest rate

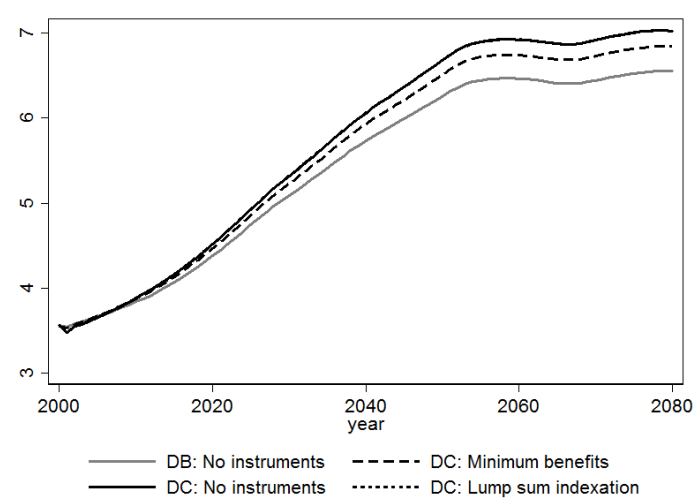

(c) capital

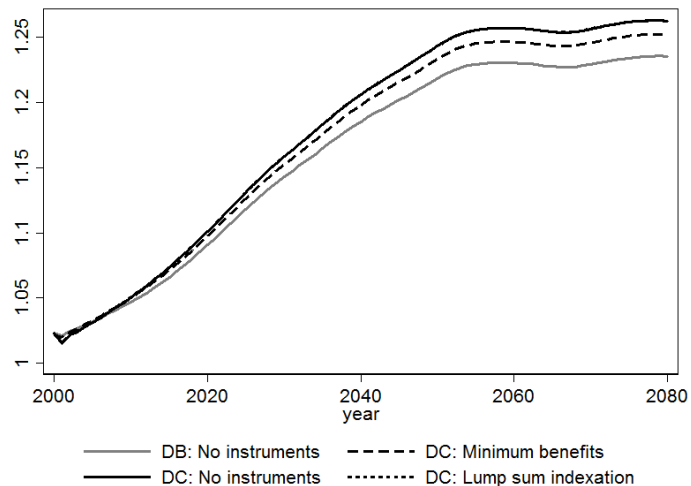

(b) wages

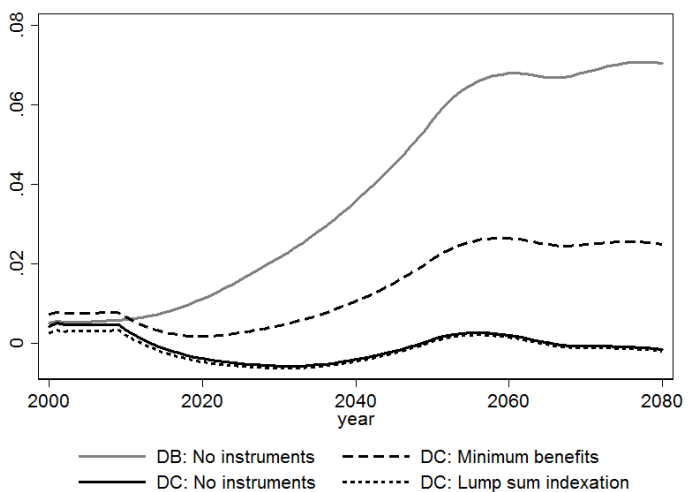

(d) pension system deficit (as \% of GDP) 
Table A3: Sources of inequality levels - at retirement in 2040

\begin{tabular}{|c|c|c|c|c|c|c|}
\hline & & $\begin{array}{l}\text { No i } \\
\text { DB }\end{array}$ & $\begin{array}{l}\text { uments } \\
\text { DC }\end{array}$ & \multicolumn{2}{|c|}{$\begin{array}{l}\text { Transition to DC with } \\
\text { minimum lump sum } \\
\text { benefits } \quad \text { indexation }\end{array}$} & $\begin{array}{c}\text { Level } \\
\text { GE DB }\end{array}$ \\
\hline & & \multicolumn{5}{|c|}{ " Consumption } \\
\hline \multirow[t]{2}{*}{ Gini coefficient } & preferences & 0.92 & 0.92 & 0.92 & 0.92 & \multirow{2}{*}{0.177} \\
\hline & endowments & 0.35 & 0.36 & 0.36 & 0.36 & \\
\hline \multirow[t]{2}{*}{ Theil index } & preferences & 0.88 & 0.87 & 0.88 & 0.87 & \multirow{2}{*}{0.052} \\
\hline & endowments & 0.12 & 0.13 & 0.13 & 0.13 & \\
\hline \multirow[t]{2}{*}{ MLD } & preferences & 0.88 & 0.88 & 0.89 & 0.88 & \multirow{2}{*}{0.055} \\
\hline & endowments & 0.12 & 0.12 & 0.12 & 0.12 & \\
\hline \multirow[t]{2}{*}{ Share bottom 20} & preferences & 1.06 & 1.06 & 1.06 & 1.06 & \multirow{2}{*}{0.120} \\
\hline & endowments & 1.45 & 1.44 & 1.44 & 1.44 & \\
\hline \multirow[t]{3}{*}{ Share top 20} & preferences & 0.98 & 0.97 & 0.97 & 0.97 & \multirow{2}{*}{0.583} \\
\hline & endowments & 0.76 & 0.77 & 0.76 & 0.77 & \\
\hline & & \multicolumn{5}{|c|}{ Wealth } \\
\hline \multirow[t]{2}{*}{ Gini coefficient } & preferences & 0.95 & 0.94 & 0.84 & 0.94 & \multirow{2}{*}{0.297} \\
\hline & endowments & 0.24 & 0.28 & 0.24 & 0.28 & \\
\hline \multirow[t]{2}{*}{ Theil index } & preferences & 0.94 & 0.92 & 0.71 & 0.92 & \multirow{2}{*}{0.149} \\
\hline & endowments & 0.06 & 0.08 & 0.06 & 0.08 & \\
\hline \multirow[t]{2}{*}{ MLD } & preferences & 0.94 & 0.92 & 0.66 & 0.92 & \multirow{2}{*}{0.183} \\
\hline & endowments & 0.05 & 0.07 & 0.05 & 0.07 & \\
\hline \multirow[t]{2}{*}{ Share bottom 20} & preferences & 1.07 & 1.05 & 1.26 & 1.05 & \multirow{2}{*}{0.071} \\
\hline & endowments & 2.40 & 1.78 & 2.16 & 1.78 & \\
\hline \multirow[t]{2}{*}{ Share top 20} & preferences & 0.95 & 0.95 & 0.91 & 0.95 & \multirow{2}{*}{0.575} \\
\hline & endowments & 0.63 & 0.68 & 0.65 & 0.68 & \\
\hline
\end{tabular}

Notes: Preferences rows stand for partial equilibrium outcomes, where endowments are fixed, but preferences vary. Endowments rows stand for partial equilibrium outcomes, where preferences are fixed, but endowments vary. All indicators expressed as a ratio to general equilibrium with both sources of inequality. Levels of corresponding inequality measures for the DB scenario displayed on the rightmost column. Measures computed at last year of working period for a cohort turning to $j=\bar{J}$ in $t=2040$. DB denotes simulations for no change in the pension system relative to the initial steady state. DC denotes transitions from an initial steady state of DB to a final steady state of DC, as described in section 2.3. MLD denotes mean log deviation. Shares of top and bottom $20 \%$ computed as all consumption / wealth accruing to a given fraction of population of age $j=\bar{J}$ in $t=2040$ divided by total consumption / wealth of population of age $j=\bar{J}$ in $t=2040$. 
Figure A3: Sources of changes in inequality due to the minimum pension benefits

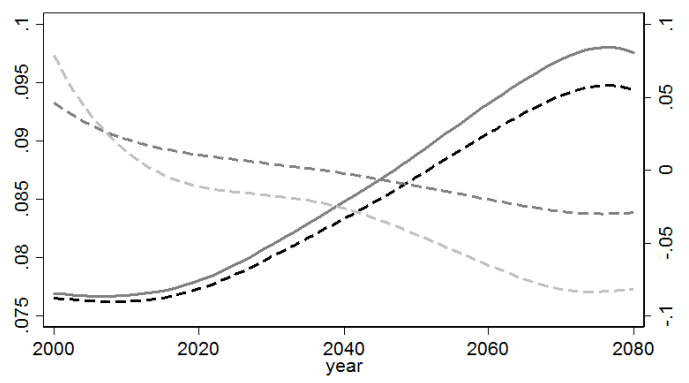

DC: No instruments

---- Influence on the preferences margin (right)

Influence on the endowments margin (right)

(a) Consumption Theil index

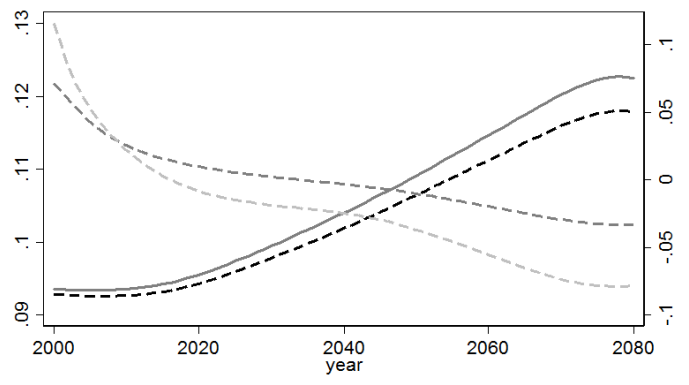

DC: No instruments

----- DC: Minimum benefits

-. - - - Influence on the preferences margin (right)

---- Influence on the endowments margin (right)

(c) Consumption mean log-deviation

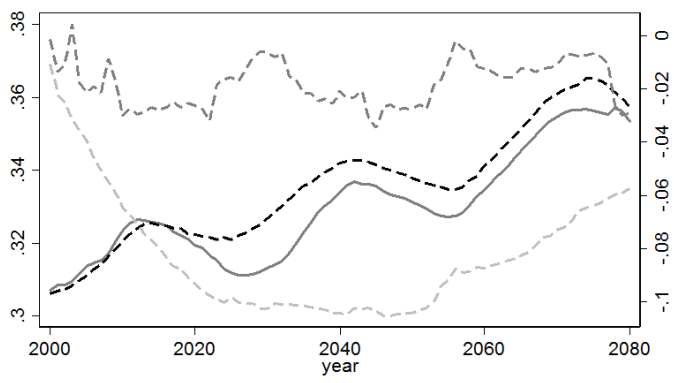

DC: No instruments
-- DC: Minimum benefits

- Influence on the preferences margin (right)

Influence on the endowments margin (right)

(b) Wealth Theil index

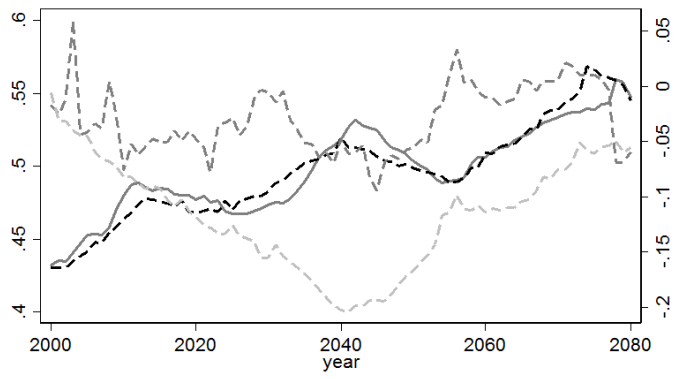

DC: No instruments

----. DC: Minimum benefits

-- - - Influence on the preferences margin (right)

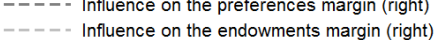

(d) Wealth mean log-deviation

Note: Solid and dashed thick lines plot the level of inequality measure in the scenario of transition to DC with no instruments and the scenario of transition to DC with minimum pension benefit, respectively. Dashed gray and light Grey lines depict the relative (percentage) difference between the reform and baseline scenarios under partial equilibrium with only one dimension of heterogeneity: either preference heterogeneity (dashed black line) or endowment heterogeneity (dashed gray line). 